\title{
Sediment Isotope Tomography (SIT) Model Version 1
}

March 1996

J. Carroll and J.D. Abraham
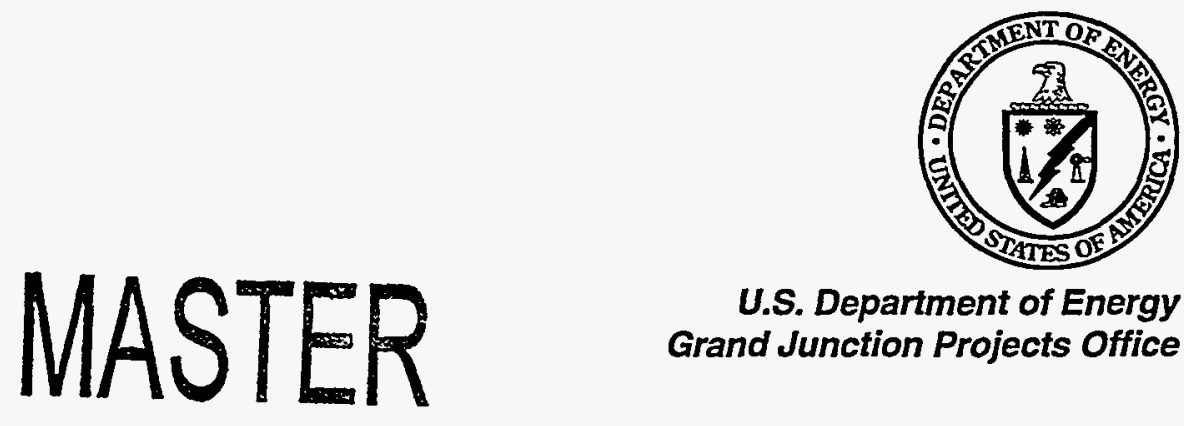

U.S. Department of Energy Grand Junction Projects Office 
This report was prepared as an account of work sponsored by an agency of the United States Government. Neither the United States Government nor any agency thereof, nor any of their employees, makes any warranty, express or implied, or assumes any legal liability or responsibility for the accuracy, completeness, or usefulness of any information, apparatus, product, or process disclosed in this report, or represents that its use would not infringe privately owned rights. Reference herein to any specific commercial product, process, or service by trade name, trademark, manufacturer, or otherwise, does not necessarily constitute or imply its endorsement, recommendation, or favoring by the United States Government or any agency thereof. The views and opinions of authors expressed herein do not necessarily state or reflect those of the United States Government or any agency thereof. 
DISCLAIMER

Portions of this document may be illegible in electronic image products. Images are produced from the best available original document. 


\section{Sediment Isotope Tomography (SIT) Model Version 1}

J. Carroll and J.D. Abraham

March 8, 1996

Prepared for

U.S. Department of Energy

Albuquerque Operations Office

Grand Junction Projects Office

Prepared by

Rust Geotech

Grand Junction, Colorado 


\section{Table of Contents}

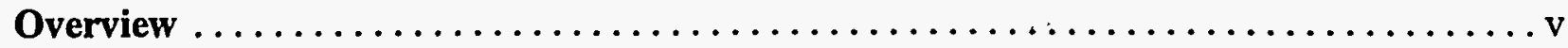

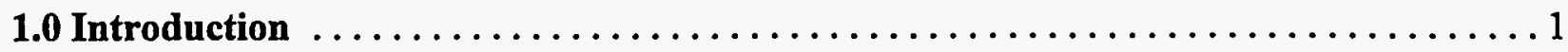

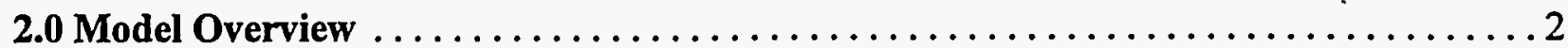

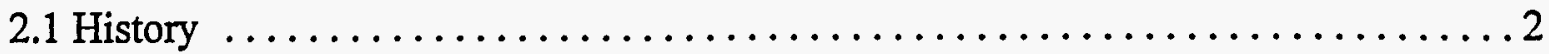

2.2 Alternative Models . . . . . . . . . . . . . . . . . . . . . . . . . . . . . 3

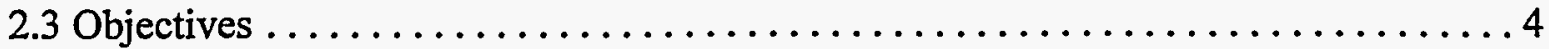

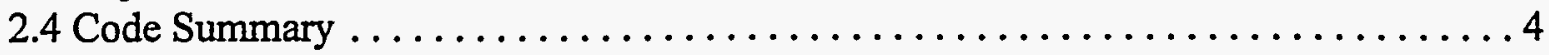

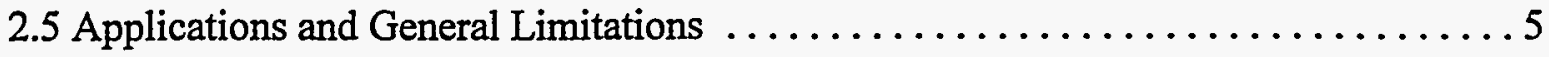

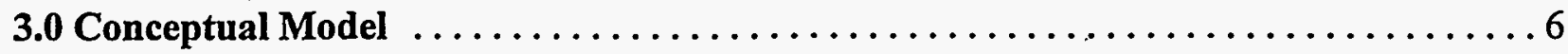

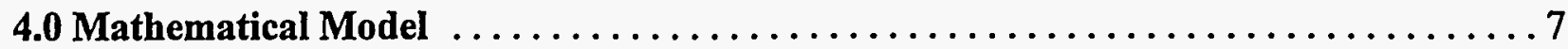

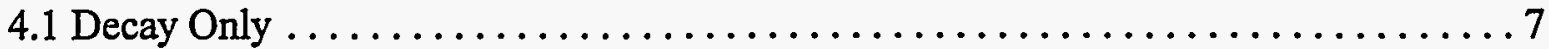

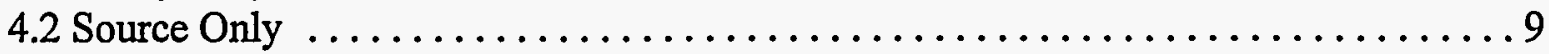

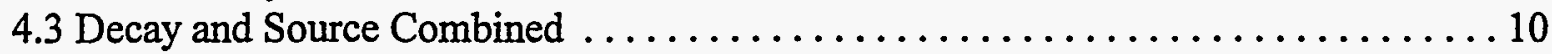

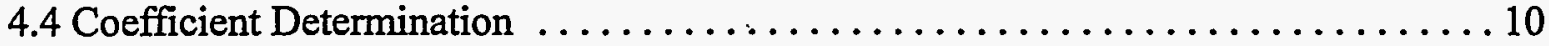

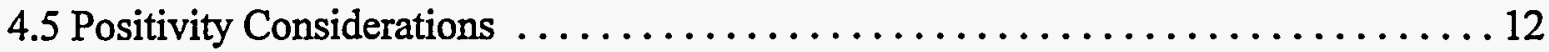

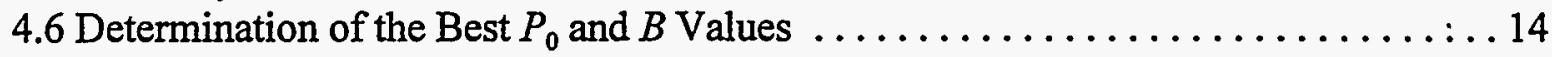

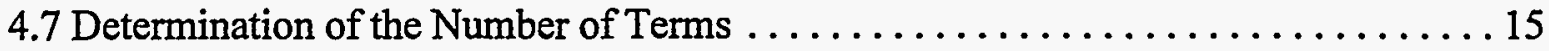

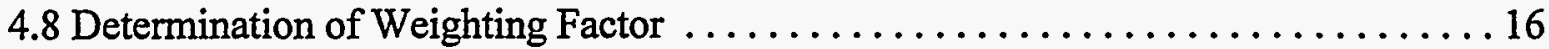

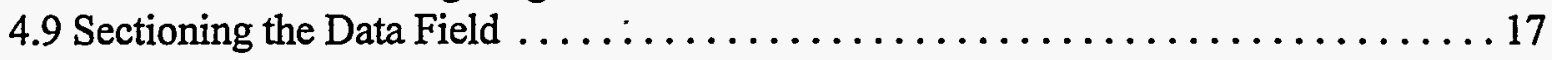

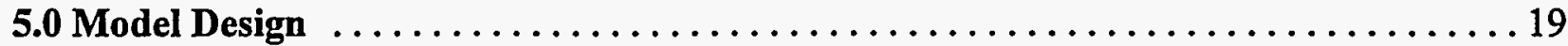

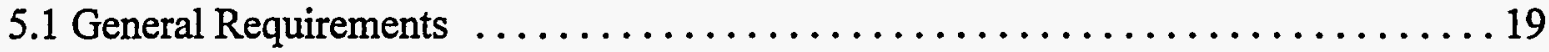

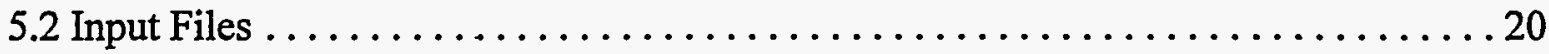

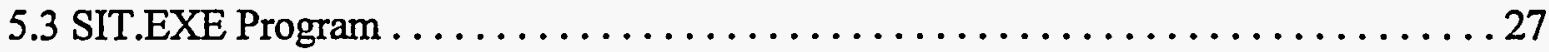

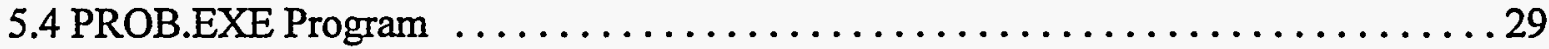

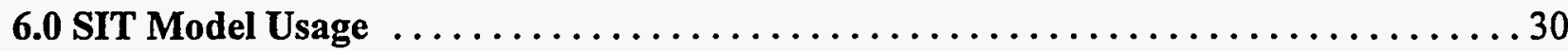

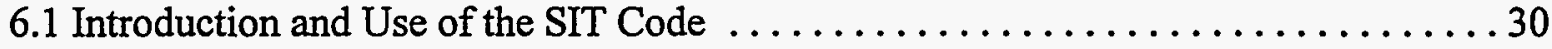

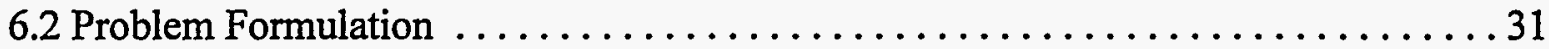

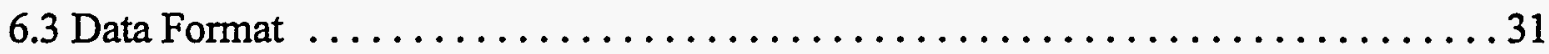

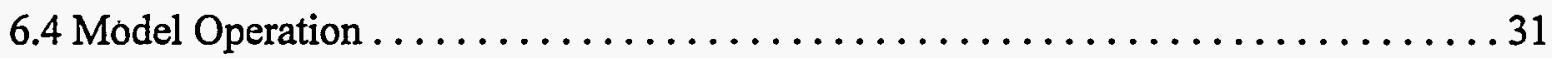

7.0 Example Simulations . .................................... 34

7.1 Example 1: Constant Sediment Accumulation Rate/Constant Isotopic Flux . . . . . 34

7.2 Example 2: Variable Sediment Accumulation Rate/Variable Flux Rate ........ 36

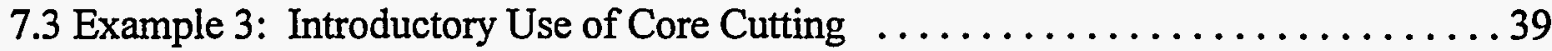

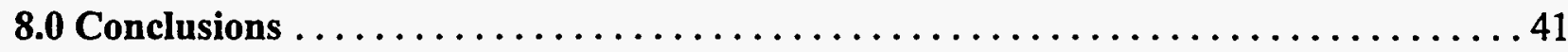


10.0 References

\section{List of Figures}

Figure $5-1$. Generalized Flow of the SIT Simulation $\ldots \ldots \ldots \ldots \ldots \ldots \ldots \ldots$

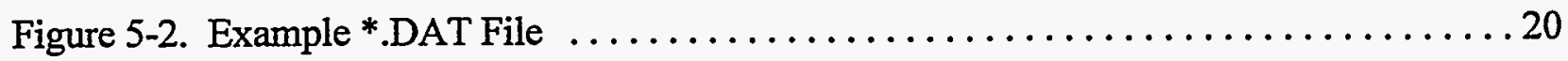

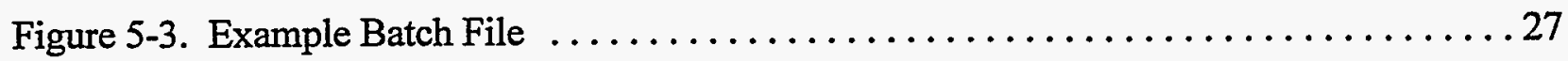

Figure $5-4$. Example of Linear Search Output $\ldots \ldots \ldots \ldots \ldots \ldots \ldots \ldots \ldots \ldots$

Figure 7-1. Graphical Results of Example One $\ldots \ldots \ldots \ldots \ldots \ldots \ldots \ldots \ldots \ldots$

Figure 7-2. Graphical Results of Example Two $\ldots \ldots \ldots \ldots \ldots \ldots \ldots \ldots \ldots \ldots \ldots \ldots$

Figure 7-3. Graphical Results of Example Three $\ldots \ldots \ldots \ldots \ldots \ldots \ldots \ldots \ldots \ldots$

\section{List of Tables}

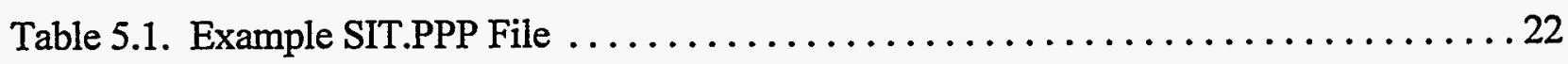




\section{Overview}

The Sediment Isotope Tomography (SIT) model has been developed as an MS-DOS-based computer software program to analyze complex depth profiles of radioisotope activity measured in marine and freshwater sediment cores. The model is designed to reconstruct the history of unmixed sediment deposition and to recover past events, such as human impacts and natural chemical alterations, that are preserved in buried sediments. The approach, based on the SIT model, applies inverse numerical analysis techniques to disentangle components of variations in radioisotope activity with sediment depth caused by variations in sediment accumulation rate and radioisotope flux. This report is a user's guide for the SIT model that includes the basis for the conceptual model and its numerical implementation, simulations using sample data sets, and the input and output listings from these simulations. A 3.5-inch diskette containing the software for the SIT model is provided in a pocket on the inside back cover of this report.

To use the SIT model software successfully, the following system requirements should be met:

- Computer: IBM-compatible PC

- CPU: 80386 minimum; 80486 recommended

- Coprocessor: Recommended

- Hard Drive: 2 to 5 Megabytes (M) recommended

- Floppy Disk Drive: 1.2 or $1.44 \mathrm{M}$

- Monitor: CGA; VGA recommended

- Printer/Plotter: Not supported

- Mouse: Not supported

- MS-DOS: Version 5.0 


\subsection{Introduction}

Geochronology using ${ }^{210} \mathrm{~Pb}$ is the principal method used to quantify sediment accumulation in rapidly depositing aquatic environments such as lakes, estuaries, continental shelves, and submarine canyons (Chanton et al. 1989; Kuehl et al. 1986; Nittrouer et al. 1983; DeMaster and Cochran 1982; Benninger et al. 1979; Smith and Walton 1980; Goldberg et al. 1978; Koide et al. 1973; Koide et al. 1972). This method is based on the radioactive decay of ${ }^{210} \mathrm{~Pb}$ with depth in a column of sediment. The decay through time of ${ }^{210} \mathrm{~Pb} P(t)$ is governed by the exponential law

$$
P(t)=P_{0} \exp (-\lambda t)
$$

where $P_{0}$ is the surficial concentration at time $t=0$, and $\lambda$ is the decay constant $\left(3.114 \cdot 10^{-2}\right.$ year $[\mathrm{yr}]^{-1}$ for ${ }^{210} \mathrm{~Pb}$ ). If the sedimentation rate is constant, then elapsed time $t$ is connected to burial depth $x$, through $x=V t$ where $V$ is the sedimentation velocity. Accordingly,

$$
P(x)=P_{0} \exp (-\lambda x / V)
$$

The sedimentation velocity is obtained from an exponential fit to the measured ${ }^{210} \mathrm{~Pb}$ data $P(x)$, with depth $x$.

Observations indicate that equation (1-2) is not adequate to describe a large percentage of ${ }^{210} \mathrm{~Pb}$ profiles. Even if the sedimentation velocity is constant, processes occur independently of sedimentation rate that influence ${ }^{210} \mathrm{~Pb}$ profiles, including (1) later compaction of the sediments after burial, which will ensure that the depth-to-age conversion is not constant; (2) biological and physical mixing, which can redistribute sediments after burial; and (3) intrinsic variations in sediment ${ }^{210} \mathrm{~Pb}$ activity, which occur in response to sediment diagenesis, changes in ${ }^{210} \mathrm{~Pb}$ activity in seawater, and changes in sediment composition. In addition, the rate of sedimentation can vary with time.

This document describes an approach, using the Sediment Isotope Tomography (SIT) model (Carroll and Lerche 1990; Carroll and Learch 1991; Liu et al. 1991) that expands the application of ${ }^{210} \mathrm{~Pb}$ geochronology to include more complex ${ }^{210} \mathrm{~Pb}$ profiles. In this technique, nonexponential changes in ${ }^{210} \mathrm{~Pb}$ activity caused by sedimentation are modeled with a Fourier sine series; changes caused by other processes are modeled by a Fourier cosine series. The values of the Fourier coefficients are determined for the measured data by inverse numerical analysis that yields a mathematical expression describing changes in ${ }^{210} \mathrm{~Pb}$ activity with sedimentary depth. This report is a user's guide for the SIT model that includes the basis for the conceptual model and its numerical implementation, simulations using sample data sets, and the input and output listings from these simulations. A 3.5-inch diskette containing the software for the SIT model is provided in a pocket on the inside back cover of this report. 


\subsection{Model Overview}

\subsection{History}

${ }^{210} \mathrm{~Pb}$ was first recognized as a potential geochronometer of sedimentation by Goldberg (1963). Subsequently, Krishnaswamy et al. (1971) used ${ }^{210} \mathrm{~Pb}$ to determine accumulation rates in lake sediments. The initial use of ${ }^{210} \mathrm{~Pb}$ in the marine environment was in the Santa Barbara Basin where sediment accumulation rates based on ${ }^{210} \mathrm{~Pb}$ geochronology were verified by varve geochronology (Koide et al. 1972). Later, Koide et al. (1973) determined sediment accumulation rates for unvarved sediments in Baja California. Goldberg and Bruland (1974) subsequently reviewed the early development of ${ }^{210} \mathrm{~Pb}$ as a geochronometer and the general assumptions of radioactive dating. These early studies established the basic application of ${ }^{210} \mathrm{~Pb}$ to studies of sediment accumulation.

As more ${ }^{210} \mathrm{~Pb}$ sediment profiles were acquired, it became apparent that steady-state assumptions [equations (1-1) and (1-2)] were not applicable in a variety of sedimentary environments. Empirical models were developed to correct for known environmental effects on ${ }^{210} \mathrm{~Pb}$ profiles. Various models were designed to correct for mixing, sediment compaction, changing accumulation rates, and changing sediment ${ }^{210} \mathrm{~Pb}$ activities (Gardner et al. 1987; Christensen 1982; Officer 1982; Robbins 1978; Appleby and Oldfield 1978; Goldberg 1963; Goldberg and Koide 1962). These models (see Section 2.2) predict the effects of sedimentation and source processes on the distribution of ${ }^{210} \mathrm{~Pb}$, so that an equation describing the ${ }^{210} \mathrm{~Pb}$ distribution is solved explicitly for the sediment accumulation rate. These models work reasonably well in cases where the rate of sediment accumulation is constant and also work in a few restrictive cases where the rate of sediment accumulation is only slightly variable. However, the determination of accumulation rates becomes impractical when the precise nature of the processes controlling the ${ }^{210} \mathrm{~Pb}$ sediment profile are not well known or understood.

The SIT model represents a departure from these approaches because (1) it uses an iterative approach to determine model parameters that reproduce the radionuclide concentration with the depth profile and (2) the model does not require a priori knowledge of the exact causes of variations in radionuclide concentration with depth. This model was first used to construct ${ }^{87} \mathrm{Sr} /{ }^{86} \mathrm{Sr}$ activity ratios with depth and time (Carroll and Lerche 1990; 1991). Liu et al. (1991) conducted the first test of the model on ${ }^{210} \mathrm{~Pb}$ profiles for sediment cores collected from the delta of the Amazon River. The computer code and conceptual approach were revised from 1992 to 1995 , and the computer code was rewritten in the " $\mathrm{C}$ " computer language. The new code shows improvements in the accuracy and efficiency of the numerical algorithms. Carroll et al. (1995) conducted computer experiments on synthetic data profiles to demonstrate that the new approach accurately reconstructs sediment burial histories in a variety of simulated sedimentary regimes. Several data sets, previously published in the literature exhibiting unusual ${ }^{210} \mathrm{~Pb}$ behavior, were reanalyzed to examine the overall utility and effectiveness of the model (Carroll et al. 1996). The results demonstrate the applicability of the SIT model in a wide range of complex depositional environments. This user's guide and the associated publications on the SIT model (Carroll and Lerche 1990; 1991; Liu et al. 1991; Carroll et al. 1995; Carroll et al. 1996) provide a complete history of the development of this new approach to analyzing radionuclide profiles. 


\subsection{Alternative Models}

Empirical models rely on assumptions concerning the relationships among the time rate of change of the specific activity $A_{S}(t)$ of ${ }^{210} \mathrm{~Pb}$ measured in disintegrations per minute (dpm) per gram (g); the flux $F(t)$ of unsupported ${ }^{210} \mathrm{~Pb}$ from seawater to sediments (dpm/centimeter [cm] ${ }^{-2}$ $\left.\mathrm{yr}^{-1}\right)$; and the sediment accumulation rate, $R(t)$ in $\mathrm{g} / \mathrm{cm}^{-2} \mathrm{yr}^{-1}$, such that, at the time of sediment deposition,

$$
A_{s}(t)=F(t) / R(t)
$$

A major drawback of the empirical models. is that they are only applicable if additions or losses of radioactivity do not occur after burial. Specific empirical models are discussed in more detail in the following subsections.

\subsubsection{Simple Model}

The simple model, also termed the Constant Flux/Constant Sedimentation (CFCS) Model (Appleby and Oldfield 1978), is applied to ${ }^{210} \mathrm{~Pb}$ profiles when the flux of unsupported ${ }^{210} \mathrm{~Pb}$ from seawater to sediment is constant and also when the sedimentation rate is constant (Robbins 1978). The model is similar to equation $(2-1)$; however, ${ }^{210} \mathrm{~Pb}$ activity $P(m)$ varies with the cumulative dry-mass of sediment $m$ instead of with sediment depth $x$, such that

$$
P(m)=P_{0} \exp (-\lambda m / V)
$$

where the velocity $V$ is the rate of grammage added per unit time. This approach is necessary to correct the accumulation rate for changes in sediment porosity caused by the compaction of sediment after burial.

\subsubsection{Constant Flux Model}

This model was first developed by Goldberg (1963). In later applications, Robbins (1978) coined the term the Constant Flux (CF) model, and Appleby and Oldfield (1978) labeled the model as the Constant Rate of Supply (CRS) model. The CF model is applied when sedimentation rates are variable in time but the flux of ${ }^{210} \mathrm{~Pb}$ to sediments remains constant (Robbins 1978). The excess ${ }^{210} \mathrm{~Pb}$ profile vertically integrated to a depth $x$ (or alternatively, cumulative dry-mass $m$ ) will equal the flux (constant) integrated over the corresponding time interval. Integrating with depth $x$, the governing equation is

$$
A(x)=A_{0} \exp (-\lambda t)
$$

where $A(x)$ is the cumulative residual unsupported ${ }^{210} \mathrm{~Pb}$ activity beneath sediments of depth $x$, and where $A_{0}$ is the total unsupported ${ }^{210} \mathrm{~Pb}$ activity in the sediment column. The age of sediments at depth $x$ is then

$$
t=(1 / \lambda) \ln \left[A_{0} / A(x)\right]
$$


and the sedimentation velocity $V$ at each time is,

$$
V=\lambda A(x) / P(x)
$$

where $P(x)$ is the unsupported ${ }^{210} \mathrm{~Pb}$ activity at depth $x$.

\subsubsection{Constant Specific Activity Model}

The Constant Specific Activity (CSA) model (Robbins 1978) or the Constant Initial Activity (CIA) model (Appleby and Oldfield 1978) assumes that sediments have a constant initial unsupported ${ }^{210} \mathrm{~Pb}$ activity. This model is applicable when sediments supplied to the seabed contain equal activities of unsupported ${ }^{210} \mathrm{~Pb}$ and when the sedimentation rate is variable with time. The unsupported ${ }^{210} \mathrm{~Pb}$ activity $P(x)$ at depth $x$ is then related to the surface sediment activity $P_{0}$ by the relationship

$$
P(x)=P_{0} \exp (-\lambda t)
$$

\subsection{Objectives}

The two major objectives of the SIT model are to analyze depth profiles of radionuclides (1) to determine the relationship between sediment depth and time and (2) to quantify sedimentation rate and flux variations with time. This information is used to interpret sediment accumulation and contaminant storage processes in aquatic bottom deposits. For the SIT model to accomplish these objectives, the model must reconstruct the data profile (radionuclide activity in relation to depth) within a user-defined acceptable limit of mismatch between the data and model and must satisfy other user-specified time constraints on sediment ages.

\subsection{Code Summary}

The SIT model represents changes in isotope activity $P(x)$ with depth $x$ in a sediment column as

$$
\begin{array}{cc}
\begin{array}{c}
\text { Sedimentation } \\
\text { Term }
\end{array} & \begin{array}{c}
\text { Source } \\
\text { Term }
\end{array} \\
P(x)=P_{0} \exp \left(\left[-B x+\sum_{n=1}^{N} \frac{a_{n}}{n \pi} \sin \left(\frac{n \pi x}{x_{\max }}\right)\right]+\sum_{n=1}^{N} \frac{b_{n}}{n \pi}\left[1-\cos \left(\frac{n \pi x}{x_{\max }}\right)\right]\right)
\end{array}
$$

where summations are for $n=1,2,3, \ldots, N ; a_{n}$ and $b_{n}$ refer to sedimentation and source ; $x_{\max }$ is the greatest depth of measurement; and $B$ is a trend coefficient related to the average sedimentation speed $V$, where $B=\lambda / V$.

Over a given depth section, there is some average sedimentation speed $V$ plus variations around the average. The variations in velocity are represented by a Fourier cosine series because the variations around the average sediment accumulation rate must themselves have a zero average. A cosine series automatically accomplishes this task. Note that the time-to-depth variation is 
then described by a term that is linear in depth and by sine oscillations [equation (2-7)].

The SIT model represents intrinsic variations in specific activity that are unrelated to variations in the rate of sediment deposition represented by a Fourier cosine series (normalized to unit value at the sediment surface), as shown in equation (2-7). The value of the surface isotope activity, $P_{0}$, is also taken to be a variable to be determined, often within prescribed limits. The combination of all three factors yields a predicted behavior for isotopic variation with depth that depends linearly on $P_{0}$, and nonlinearly on $B$ and $N$. The factors $P_{0}, B$, and $N$ define a linear set of $2 N$ equations with $2 N$ unknowns. These equations are solved by standard matrix inversion to determine the Fourier coefficients $a_{n}$ and $b_{n}$. For each set of $P_{0}, B$, and $N$, there is a unique choice of values for the coefficients $a_{n}$ and $b_{n}$ and, hence, a unique solution to equation (2-7).

A nonlinear iteration scheme is then introduced which automatically produces values of $P_{0}, B$, and $N$ at each iteration that are guaranteed to give a predicted isotope variation with depth that is closer and closer to the observed value as iterations proceed. The iteration scheme also guarantees to keep $P_{0}, B$, and $N$ within any preset boundaries at each iteration. Iterations are stopped when a criterion of convergence is reached (i.e., the difference between predicted $[\operatorname{Pred}(x)]$ and observed values $[\operatorname{Obs}(x)]$ is less than the measurement resolution). Thus, a useful measure of fit involves the introduction of chi-squared $\left(\chi^{2}\right)$ with

$$
\chi^{2}=\sum_{i=1}^{M} \frac{\left[\operatorname{Pred}\left(x_{i}\right)-\operatorname{Obs}\left(x_{i}\right)\right]^{2}}{M}
$$

where $M$ is the number of data points.

Successful separation of sedimentation and source terms has been achieved when the model produces a satisfactory fit to the data. Sedimentation and source variations can then be plotted as functions of time or depth.

\subsection{Applications and General Limitations}

The SIT model has been successfully applied to ${ }^{210} \mathrm{~Pb}$ depth profiles from a variety of aquatic systems. For example, interpretations of the sedimentation history have been achieved for a pond contaminated with uranium mill tailings (Waugh et al.1996). Several lakes have also been investigated where water-level fluctuations have altered sediment accumulation rates through time. Some estuarine systems have been investigated as well (Carroll et al. 1996).

The ability to interpret sediment accumulation histories in environments where multiple physio-chemical processes influence the distribution of radionuclides used in the dating of sediments is an advantage over earlier interpretation techniques. However, the SIT model, like all models, has its limitations; this model cannot be used to reconstruct sediment accumulation histories in all cases. The most important limitation of this model is that it may not be used for areas where sediments are mixed, physically or biologically, over short time scales relative to the rates of sediment accumulation. In such cases, the signal of radioactive decay is erased through homogenization of the sediment profile; no inverse model is capable of recovering a signal that is 
not present. One approach that is currently being tested to interpret sediment cores where mixing predominates is to combine a forward model of sediment mixing with the inverse SIT model. However, at present, the use of the SIT model for mixed sediment profiles must be conducted with great care.

Many sediment profiles exhibit fluctuations in deposition rates at frequencies that are higher than the practical resolution limit of the core-sectioning process (about $0.5 \mathrm{~cm}$ ) or of the radionuclide itself. For example, ${ }^{210} \mathrm{~Pb}$ with a half-life of $22.26 \mathrm{yr}$ is not appropriate to interpret depositional histories in environments where the dominant frequency of accumulation rate change is seasonal. A lack of depth resolution in the core sections themselves will lead to difficulties in analyzing and interpreting model results. This difficulty may occur when ${ }^{210} \mathrm{~Pb}$ is used to interpret depositional histories in environments where excess ${ }^{210} \mathrm{~Pb}$ is only observed a few centimeters below the core surface. Lack of depth resolution may also occur when ${ }^{210} \mathrm{~Pb}$ is used in environments where the sediment accumulation rates are so high that the depth of ${ }^{210} \mathrm{~Pb} /{ }^{26} \mathrm{Ra}$ equilibrium is never observed.

To use the SIT model successfully, consideration must always be given to the characteristics of the environment under investigation, the sampling strategy to be used, and the handling of the sediment cores. As a guideline, careful description of the sedimentary structure of the core should be completed to aid in the interpretation of results. The analyses should include sedimentary structure, size distributions, bioturbation, and noticeable biogeochemical colorations or artifacts. High-depth resolution sampling of the cores for isotopic analysis increases the model's confidence level and will result in a better reconstruction of the ${ }^{210} \mathrm{~Pb}$ profile by the SIT model. Density and porosity measurements made through the length of the core are essential to properly normalize the data for compaction and for calculating radionuclide flux. Possible further chemical analysis may be needed to identify "key beds" or time markers within the sediments of the core.

Even with all reasonable precautions, cases will still exist where current methods of interpretation, such as CFCS, CSA, and SIT, are unable to satisfactorily reconstruct sediment burial histories.

\subsection{Conceptual Model}

In this section, the SIT model is presented to determine accumulation rates for a ${ }^{210} \mathrm{~Pb}$ profile that has been affected by varying rates of sediment accumulation in conjunction with confounding biogeochemical processes.

The sedimentary profile of ${ }^{210} \mathrm{~Pb}$ represents a response variable $Y$ that is the result of a set of stimulus variables $X$. The modeling task is to find some function of $X$ that approximates $Y$. Often the most difficult part of modeling is defining a model's structure - that is, the inputs to the model and how the inputs react. In the case of ${ }^{210} \mathrm{~Pb}$, processes such as sediment grain size, compaction, bioturbation, and accumulation influence the shape of $\mathrm{a}^{210} \mathrm{~Pb}$ profile. The simultaneous consideration of all of these factors is beyond the scope of current technology. 
An alternative approach to modeling ${ }^{210} \mathrm{~Pb}$ profiles is to automate the process. Properly directed, a computer can examine many possible alternative explanations for a data set. It is much more likely that a natural model form, if it exists, will emerge from the recorded data and give shape to the information. This approach is known as inductive or inverse modeling. For these models, it is critical to choose a broad parametric class from which the model will be drawn. The computer is then used to determine the form of the model from the data at hand.

Geochronology studies are concerned with deciphering that portion of the ${ }^{210} \mathrm{~Pb}$ profile resulting from the radioactive decay that has occurred since the time of sediment burial. The signal of radioactive decay is the link between sediment depth and the time since deposition. The challenge, then, is to develop an equation for $\mathrm{a}^{210} \mathrm{~Pb}$ profile that distinguishes the signal of radioactive decay from other signals.

For any ${ }^{210} \mathrm{~Pb}$ profile, a "source" term is defined as the total contribution of ${ }^{210} \mathrm{~Pb}$ by geochemical processes at each measurement depth, regardless of whether the net result is an increase or decrease in ${ }^{210} \mathrm{~Pb}$ activity with depth. A "sedimentation" term records the loss of ${ }^{210} \mathrm{~Pb}$ caused only by radioactive decay; the depth distribution of the sedimentation term does not necessarily decrease with increasing depth. A "data field" is the result of unknown combinations of source and sedimentation terms and can exhibit increases or decreases in ${ }^{210} \mathrm{~Pb}$ activity throughout the profile.

Fourier analysis is a process that is commonly used to analyze complex data records (Bendat and Piersol 1971). In Fourier analysis, bounded complex functions are expressed as a combination of sine and cosine series (Tolstov 1962). Sine and cosine series mathematically separate independent processes into their associated parts. A well-known application of this technique is separation of tidal harmonics in the prediction of the tides. Similarly, the sine (cosine) Fourier representation of sedimentation source is applicable for disentangling ${ }^{210} \mathrm{~Pb}$ sediment profiles. Equation (2-7) was designed based on the premise that the rates of sediment accumulation are in no way connected to the geochemical processes affecting the addition or removal of ${ }^{210} \mathrm{~Pb}$ activity to sediments.

\subsection{Mathematical Model}

Measurements of radioactive decay of an isotope are taken with respect to sedimentary depth $x$ measured from the sediment surface $(x=0)$ downward.

\subsection{Decay Only}

Suppose, initially, that the isotopic concentration per unit mass of solid material deposited is fixed for all time. Then the later decay with time of an isotopic concentration is governed by the exponential law

$$
P(x)=P_{0} \exp (-\lambda t)
$$

where $P_{0}$ is the surficial concentration at time $t=0$, and $\lambda$ is the intrinsic decay rate of the particular isotope. 
If the sedimentation rate is constant for all time, then elapsed time $t$ is connected to burial depth $x$ through $x=V t$, where $V$ is the sedimentation velocity. Accordingly, we can write

$$
P(x)=P_{0} \exp \left(\frac{-\lambda x}{V}\right)
$$

Hence by measuring $P(x)$, we can obtain the best velocity from an exponential fit with depth to the measured data.

For situations in which equation (4-2) is not adequate to describe the isotope data field, take the sediment velocity to vary with depth $x$ or time $t$ so that deposition is controlled by

$$
d t / d t=V(t)
$$

or, by

$$
d t=d x[S(x)]
$$

where $S(x)$ is the slowness, calculated by $S=1 / V$.

Throughout this section, the slowness formulation [equation (4-3b)] will be used. Therefore, the age of sediments currently at depth $x$ is given by

$$
t=\int_{0}^{x} d x^{\prime} \cdot S(x)
$$

where age zero $(t=0)$ corresponds to the present day at the sediment surface $(x=0)$. Split the slowness into a constant average value $B$ and a fluctuation around the average value that has a zero average. Accordingly,

$$
S(z)=B+\Delta S(z)
$$

with

$$
\int_{0}^{1} d z^{\prime} \Delta S(z)=0
$$


where the depths of the isotopic measurements are normalized so that the physical depth $x_{\max }$ of the deepest measurement corresponds to $z=1$. Accordingly,

$$
z=x / x_{\max }
$$

The choice

$$
\Delta S(z)=\sum_{n=1}^{N} a_{n} \cos (n \pi z)
$$

always satisfies equation (4-5b) and uses the fundamental Fourier series theorem that any bounded function of zero mean value can be represented by a cosine series.

Equation (4-4) then yields the age-to-depth equation

$$
t=x_{\max }\left[B z+\sum_{n=1}^{N} \frac{a_{n}}{n \pi} \sin (n \pi z)\right]
$$

Equation (4-8) provides a general connection between depth and age that removes the restriction of constant velocity. Note that no procedure has been given to determine the number of terms $N$ needed to define a given data field.

\subsection{Source Only}

The implicit assumption of a constant isotopic concentration per unit mass of sediment deposited is invalid in a large number of cases because isotopic concentrations do show localized maxima with depth. If the effects of radioactive decay and sedimentation rate variations are held constant, it follows that a variation in isotopic concentration with depth would be due to intrinsic source variations over time. With such source variations, there is no fundamental physical reason that the source should be larger or smaller than the present day surficial value $P_{0}$. The only requirement is that any source variation should be positive.

To handle all such problems, simultaneously introduce the function

$$
F(z)=\sum_{n=1}^{N} \frac{b_{n}}{n \pi}[1-\cos (n \pi z)]
$$

and write the source variation alone as

$$
P(z)=P_{0} \exp [F(z)]
$$

This choice has several advantages: (1) at $z=0$, the sediment surface is $F=0$, so $P(z=0)=P_{0}$; 
(2) $\exp [F(z)]$ is positive no matter what choices are made for the coefficients $b_{n}$ and the number of terms $(N)$ to use in describing the source variation; and (3) the fundamental Fourier theorem guarantees that the cosine series will describe any bounded variation of a function that has a nonzero mean value.

\subsection{Decay and Source Combined}

By combining the radioactive decay behavior and the source variation behavior, the general form of the equation is

$$
P(z)=P_{0} \exp [t(z)+F(z)]
$$

If the coefficients $B, a_{n}$, and $b_{n}(n=1,2,3 \ldots, N)$ can be determined from a data set, then the source variation with time is determined parametrically through $\tau(z)$

$$
\tau(z) \boxminus \lambda t=B z+\sum_{n=1}^{N} \frac{a_{n}}{n \pi} \sin (n \pi z)
$$

and

$$
\text { Source }(t)=\exp [F(t)]
$$

where $z$ values are used in equation (4-12) to construct a conversion of $z$ to time $t$ and are then used in equation (4-13) to directly express the source with time variation.

\subsection{Coefficient Determination}

Coefficient determination involves obtaining a procedure that can determine the parameters $P_{0}$, $B, N, a_{n}$ and $b_{n}$ from a data set of isotope measurements with depth as well as ascertaining the best correspondence to the data. Once these parameters and best fit have been identified, the variation of sediment rate $d z / d t$ with time or depth is easily determined from equation (4-12), as is the source variation [from equation (4-13)].

The development of a least-squares procedure to handle such problems is relatively straightforward, albeit tedious. 
Differentiate equation (4-11) with respect to $z$ to obtain

$$
\frac{d P}{d z}=P(z)\left[\frac{d \tau(z)}{d z}+\frac{d F}{d z}\right]
$$

Multiply equation (4-14) by $P(z) \exp (i k \pi z)$ and integrate over the domain $0 \leq z \leq 1$. Then separate real and imaginary parts for each value of $k$.

Real Part:

$$
\sum_{n=1}^{N} a_{n} M_{n k}+\sum_{n=1}^{N} b_{n} Q_{n k}=R_{k}(k=0,1, \ldots, N)
$$

with

$$
\begin{aligned}
M_{n k} & =2 \int_{0}^{1} P(z)^{2} \cos (n \pi z) \cos (k \pi z) d z \\
Q_{n k} & =2 \int_{0}^{1} P(z)^{2} \cos (k \pi z) \cos (n \pi z) d z
\end{aligned}
$$

and

$$
R_{k}=P(z=1)^{2}(-1)^{k}-P_{0}^{2}=k \pi \int_{0}^{1} P(z)^{2} \sin (k \pi z) d z-2 B \int_{0}^{1} P(z)^{2} \cos (n \pi z) d z
$$

Imaginary Part:

$$
\sum_{n=1}^{N} a_{n} S_{n k}+\sum_{n=1}^{N} b_{n} T_{n k}=U_{k}(k=0,1, \ldots, N)
$$

with

$$
\begin{gathered}
S_{n k}=2 \int_{0}^{1} P(z)^{2} \cos (n \pi z) \sin (k \pi z) d z \\
T_{n k}=2 \int_{0}^{1} P(z)^{2} \sin (n \pi z) \sin (k \pi z) d z
\end{gathered}
$$


and

$$
U_{k}=-k \pi \int_{0}^{1} P(z)^{2} \cos (k \pi z) d z-2 B \int_{0}^{1} P(z)^{2} \sin (k \pi z) d z
$$

Equations (4-15) and (4-17) provide a linear set for determination of the coefficients $a_{n}$ and $b_{n}$. Indeed for $k=2 N$ (and $P_{0}$ and $B$ prescribed), equations (4-15) and (4-17) provide precisely $2 N$ equations for the $2 N$ unknowns $\left(a_{1}, a_{2}, \ldots, a_{n} ; b_{1}, b_{2}, \ldots, b_{n}\right)$. Hence, standard matrix inversion methods (Menke 1984) can be used to determine the coefficients $a_{n}$ and $b_{n}$.

This procedure is followed initially to make first estimates of $a_{n}$ and $b_{n}$ for given but variable values of $P_{0}, B$, and $N$.

With the sets $\left\{a_{n}\right\}$ and $\left\{b_{n}\right\}(n=1, \ldots, N)$ determined as above, it might appear that the separation of source and sediment variations is completely disentangled. However, three factors still need to be addressed to maximize resolution:

(1) Positivity Considerations -There is an implicit requirement that the observed sediment deposition rate, deduced from the observations and the inverse matrix procedure, be intrinsically positive (i.e., $d z / d t$ [from equation (4-12)] must be greater than or equal to zero). However, this requirement has not been enforced in the least-squares approach. It can, and does, happen that finite data sampling or uncertainty in data quality-together with different choices for $P_{0}, B$, and $N$-can lead to a situation in which $d t / d z$ [from equation (412)] becomes negative over select intervals of $z$. Such behavior is physically unacceptable.

(2) Determination of the Best $\boldsymbol{P}_{\mathbf{0}}$ and $B$ Values - There still has been no procedure provided for selecting $P_{0}$ and $B$ in such a way as to guarantee that a minimum mismatch of predictions and observations can be attained to maximize the statistical sharpness of separating source and sediment variation effects.

(3) Determination of the Number of Terms - There has been no procedure given for constructing the number of terms $N$ needed to best satisfy a given data set.

The following sections will address the three factors related to maximizing the resolution of the separation of source and sediment variations.

\subsection{Positivity Considerations}

From equation (4-12), introduce

$$
\tau_{0}(z)=B z+\sum_{n=1}^{N} \frac{a_{n}}{n \pi} \sin (n \pi z)
$$




$$
\frac{d \tau_{0}}{d z}=B+\sum_{n=1}^{N} a_{n} \cos (n \pi z) \equiv B\left(\frac{d \tau_{0}}{d z}+1\right)
$$

Then, in place of $\tau(z)$ in equation (4-14), write

$$
\tau(z)=B \int_{0}^{z}\left[1+2\left|\frac{d \tau_{0}}{d z}\right|\right]^{\frac{1}{2}} d z^{\prime} \equiv B \tau^{\prime}(z)
$$

and

$$
\delta \tau(z)=\tau(z)-\tau_{0}(z)
$$

so that the age-to-depth conversion is provided by equation $(4-20)$ with $\tau(z)=\tau(z) / \lambda$. Notice that the nonlinear function [equation (4-20)] guarantees that $\tau(z)$ will always be a positive increasing function of depth (i.e., the accumulation rate will be positive). However, the introduction of this nonlinear variation then changes the determination of the coefficients $a_{n}$ and $b_{n}$ from the procedure outlined in equations (4-14) through (4-18).

Tracing through the derivation of the least-squares difference procedure above, with the form [equation (4-20)] for $\tau(z)$, yields the left-hand sides of equations (4-15) and (4-17) for determining $a_{n}$ and $b_{n}$; the right-hand sides have additional terms added from the nonlinear behavior of $\tau(z)$. Thus we add to $R_{k}$ the term

$$
\begin{gathered}
\delta R_{k}=2 B \int_{0}^{1} P(z)^{2}\left[\frac{d \tau^{\prime}(z)}{d z}-1-\frac{d \tau_{0}(z)}{d z}\right] \cos (k \pi z) d z \equiv \\
2 B \int_{0}^{1} P(z)^{2}\left[\left(1+2\left|\frac{d \tau^{\prime}(z)}{d z}\right|\right)^{\frac{1}{2}}-1-\frac{d \tau_{0}(z)}{d z}\right] \cos (k \pi z) d z
\end{gathered}
$$

and we add to $U_{k}$ the term

$$
\delta U_{k}=2 B \int_{0}^{1} P(z)^{2}\left[\frac{d \tau^{\prime}(z)}{d z}-\frac{d \tau_{0}(z)}{d z}-1\right] \sin (k \pi z) d z
$$


For given values of $P_{0}, B$, and $N$, the procedure for solving equations (4-15) and (4-17) (modified by the nonlinear terms $\delta R_{k}$ and $\delta U_{k}$ ) is as follows:

(1) First ignore the terms $\delta R_{k}$ and $\delta U_{k}$, solve equations (4-15) and (4-17) to obtain first approximations to $a_{n}$ and $b_{n}$.

(2) Use these approximate values in equations (4-22) and (4-23) to obtain first approximations to $\delta R_{k}$ and $\delta U_{k}$.

(3) Add these corrections to $R_{k}$ and $U_{k}$, respectively, and then resolve equations (4-15) and (4-17) with the modified $R_{k}$ and $U_{k}$ terms, obtaining the next approximations to $a_{n}$ and $b_{n}$.

(4) Use these to update $\delta R_{k}$ and $\delta U_{k}$. Repeat the procedure until no further significant change takes place in $a_{n}$ and $b_{n}$ at the level of numerical precision of the least squares determinations of $\tau(z)$,

$$
\left|\tau_{q}(z)-\tau_{q-1}(z)\right|<\varepsilon
$$

(i.e., if, after $q$ iterations, $\varepsilon$ is a preset level of significance, then the determination of $a_{n}$ and $b_{n}$ is deemed satisfactory).

Thus, a $\tau(z)$ has now been obtained for any values of $P_{0}, B, N$, which is manifestly positive and increasing with increasing $z$, as required.

\subsection{Determination of the Best $P_{0}$ and $B$ Values}

While the determination of a time-to-depth conversion and a positive source are now guaranteed, a method is needed to estimate the values of $P_{0}$ and $B$ that is most consistent with the observed isotopic variations with depth for a specified $N$.

A procedure for guaranteeing that progressively better values of $P_{0}$ and $B$ are determined operates as follows.

Specify a search range for $P_{0}$ and $B$; in general, $P_{\min } \leq P_{0} \leq P_{\max } ; B_{\min } \leq B_{0} \leq B_{\max }$.

Introduce the normalized variables $A$ and $b$ through

$$
=\frac{P_{\max }-P_{0}}{P_{\max }-P_{\min }}, b=\frac{B_{\text {max }}-B}{B_{\max }-B_{\mathrm{r}}}
$$

so that $1 \geq A \geq 0,1>b \geq 0$.

Then construct

$$
\chi^{2}(A, b)=\frac{1}{\dot{Q}} \sum_{r=1}^{Q}\left[P\left(z_{r}\right)-P_{r}\right]^{2}
$$


where $Q$ is the number of measurement points, $P_{r}$ is the measured value at depth $z_{r}$, and $P\left(z_{r}\right)$ is the predicted value of $P(z)$ from equation (4-11) for a specified $A, b\left(P_{0}, B\right)$ pair for a given $N$. Then construct the updated values

$$
\begin{aligned}
& A_{(s+1)}=A_{s} \exp \left[-\alpha \frac{\partial \chi^{2}\left(A_{s}, b_{s}\right)}{\delta A_{s}}\right] \\
& b_{(s+1)}=b_{s} \exp \left[-\beta \frac{\partial \chi^{2}\left(A_{s}, b_{s}\right)}{\delta b_{s}}\right]
\end{aligned}
$$

with

$$
\begin{gathered}
\alpha=\left|\frac{\partial \chi^{2}\left(A_{0}, b_{0}\right)}{\delta A_{0}}\right| \ln \left[1+\frac{1}{\left(k A_{0}\right)}\right] \\
\beta=\left|\frac{\partial \chi^{2}\left(A_{0}, b_{0}\right)}{\delta b_{0}}\right| \ln \left[1+\frac{1}{\left(k b_{0}\right)}\right]
\end{gathered}
$$

where $k$ is the number of times $s$ is to be increased, and where $A_{0}$ and $b_{0}$ are the initial values of $A$ and $b$ chosen in the search ranges.

This procedure guarantees that if $A$ and $b$ are chosen to be initially positive, then they will remain positive and guarantees that at each iteration of $s$, the new values of $A$ and $b$ will come closer and closer to providing a minimum in $\chi^{2}$ (i.e., in the mismatch between observations and predicted values). A limiting behavior is obtained when the numerical accuracy is reached that allows the calculation of derivatives with respect to $A$ and $b$.

\subsection{Determination of the Number of Terms}

For each $N$ value used, application of the above procedure provides a least-squares match to the data. The mismatch at each $N$ is recorded by $\chi^{2}$. Determination of an optimal number of terms to use is then achieved by sequentially increasing $N$, running through the above procedures and recording $\chi^{2}(N)$. As $N$ increases, $\chi^{2}(N)$ first goes through a minimum and then either levels off or rises again. If $\chi^{2}$ rises as $N$ increases, then it is fairly obvious which $N$ gives the lowest $\chi^{2}$, providing a minimum mismatch. If $\chi^{2}$ levels off so that no further significant improvement in 
mismatch to the data can be obtained, then the proper inference is that there is no point in continuing to increase the $N$ beyond that value of $N$ which first reaches the leveling position, because the coefficients are then underdetermined.

The application of all of these procedures together guarantees that source and sediment variations are maximally disentangled; that source variations with time and sediment deposition rates with time are intrinsically positive; that the present day surface value and the trend value of mean sedimentation rate are maximally consistent with the data; and that the best number of terms have been used consistent with data resolution.

\subsection{Determination of Weighting Factor}

Two factors dictate that, while the procedures given guarantee a minimum least-squares fit, the fit to the data is not necessarily optimal. First, if the data show an increase over restricted ranges of depths, then there was a source variation, yet nowhere has this information been used. Second, it will be noted that equation (4-14) was multiplied by $P(z) \exp (i k \pi z)$ and integrated to obtain a least-squares set of equations for the unknown coefficients. Equation (4-14) could have been multiplied by any function, not just by $P$. For example, equation (4-14) could have been directly integrated. Note also that if $P$ is increasing, then equation (4-14) requires $d F / d z$, be less then $d t / d z$ in that domain of increase so that equation (4-14) contains the information on source variation. Yet this information is distorted if the least-squares approach is taken (the information is distorted no matter what approach is taken).

To allow for these problems simultaneously in a manner that improves the data fit, introduce the weight factor $w$ so that $P(z)=P_{0} \exp [-t(z)(1-w)+F(z)(1+w)]$. If $w=0$, source variation and radioactive decay factors are equally balanced. If $w=1$, then only the source variation controls the behavior. If $w=-1$, only the radioactive decay plays a role. The weight factor $w$ is to be constrained to lie in the domain $-1 \leq w \leq 1$.

Pragmatically, the model allows $w$ to be a parameter that is determined at the same time as parameters $P_{0}$ and $B$ are determined (see Section 4.6).

This procedure then produces a weight factor and a best fit to the data that maximally resolves the sediment and source variations with time. The procedure also allows for the uncertainties produced by errors and by finite sampling of the data as well as from upturn of the isotope 
variations with depth and the possible departure from the demands of a least-squares mismatch to the data.

\subsection{Sectioning the Data Field}

Two problems suggest that the simultaneous use of all the isotope data with all the depths of measurement may be highly inappropriate.

First, it is true that the sine and cosine series will, in principle, accurately describe any shape with an infinite $N$; however, it can and does happen that with an extremely variable profile with depth, it may take an extraordinarily large amount of computer time to find the best $N$ to use in conjunction with simultaneous determination of the best surface value, overall decay constant with depth, weight factor, and individual coefficients $a_{n}$ and $b_{n}$.

Second, the data set available to a depth $z_{D}$ is run and best parameters are computed; additions to the data set at depths in excess of $z_{D}$ become available later. These later additions should not change the determination of the present-day surface value, the age-to-depth conversion, or the source variation from the surface $(z=0)$ down to the previously computed depth at $z=z_{D}$. And yet, because the nonlinear procedure is a variant of a least-squares technique, complete restart of the system is required to redetermine all parameter values as well as the new $N$ required to fit the new total data set. This requirement also causes major increases in computer time.

Suppose then that the data field is initially and arbitrarily sectioned into two pieces: D1 occurring in $0 \leq x \leq x_{D}, \mathrm{D} 2$ in $x_{\max } \geq x \geq x_{D}$, where $x_{\max }$ is the greatest measurement depth.

Consider the data field D1 first. Assume the inverse procedure has been carried through to completion, yielding the best parameter values $P_{0}^{(1)}, B^{(1)}, N^{(1)}, a_{n}^{(1)}, b_{n}^{(1)}$ and $w^{(1)}$. Then the prediction for the data behavior (where $z=x / x_{D}$ ) is

$$
P^{(1)}(z)+P_{0}^{(1)} \exp \left[-\tau^{(1)}(z)\left(1-w^{(1)}\right)+F^{(1)}(z)\left(1+w^{(1)}\right)\right]
$$

where the superscript parameter ${ }^{(1)}$ refers to values determined from D1. Now consider the data field D2 in $x>x_{D}$. Write $Y=x-x_{D}$ so that D2 extends from $Y=0$ to $Y=Y_{\max } \equiv x_{\max }-x_{D}$. Again, fit the field $\mathrm{D} 2$ by the inverse procedure generating best parameter values $P_{0}^{(2)}, B^{(2)}, N^{(2)}$, $a_{n}^{(2)}, b_{n}^{(2)}$, and $w^{(2)}$ to obtain 


$$
P^{(2)}(y)+P_{0}^{(2)} \exp \left[-\tau^{(2)}(y)\left(1-w^{(2)}\right)+F^{(2)}(y)\left(1+w^{(2)}\right)\right]
$$

with $0<y<1$ where $y=Y / Y_{\max }$. Thus the surface value $P_{0}^{(2)}$ actually refers to the physical depth point $x=x_{D}$ while $\tau^{(2)}(y)$ and $F^{(2)}(y)$ both are zero on $y=0(x=x D)$.

From D1, a value for $P_{0}^{(2)}$ is already determined, using the following equation:

$$
P_{0}^{(2)} \equiv P^{(1)}(1)=P_{0}^{(1)} \exp \left[-\tau^{(1)}(1)\left(1-w^{(1)}\right)+F^{(1)}(1)\left(1+w^{(1)}\right)\right]
$$

The data field $\mathrm{D} 1$ should be used to construct a separation into sedimentation rate and source variations. Designate $P^{(1)}(1)$ as the constrained surface value for the data field D2. Obtain the best parameters for the sedimentation rate and source variations of $\mathrm{D} 2$.

The time-to-depth variation for the total data field is

$$
\begin{aligned}
& t^{(1)}=\left[1-w^{(1)}\right] \tau^{(1)}(z) / \lambda \text { in } 0 \leq x \leq x_{D} \quad(0 \geq z \geq 1) \\
& t^{(2)}=\left[1-w^{(2)}\right] \tau^{(2)}(z) / \lambda+t^{(1)}\left(x_{D}\right) \text { in } x_{\max } \leq x \leq x_{D} \quad(0 \geq y \geq 1)
\end{aligned}
$$

with the source component variation

$$
\begin{gathered}
S^{(1)}(x)=\exp \left[F^{(1)}(z)\left(1+w^{(1)}\right)\right] \text { in } 0 \leq x \leq x_{D} \\
S^{(2)}(x)=\exp \left[F^{(2)}(y)\left(1+w^{(2)}\right)\right] S^{(1)}\left(x_{D}\right) \text { in } x_{\max } \leq x \leq x_{D}
\end{gathered}
$$

This sectioning of the data reduces computer run time and ensures that the addition of deeper data has no effect on the time-to-depth conversion or on the source variations from shallower depths (younger times).

The sectioning into two separate partitioned data fields at $x=x_{D}$ is arbitrary, both in terms of the number of partitioned data fields and in the positioning of the partition depths. However, the resolution of the individual data measurements suggests that it is pointless to further subdivide the data fields (1) when the least-mean-squares residual mismatch per average point in a given partition is less than the measurement resolution and (2) when adding one more partition no longer improves the mismatch to the data. 


\subsection{Model Design}

\subsection{General Requirements}

The SIT model was configured to run on an IBM-compatible computer in base memory. The SIT model consists of three main parts: (1) input files, (2) the SIT.EXE program, and (3) the PROB.EXE program (Figure 5-1). The executable programs were coded and compiled by using Borland Turbo $\mathrm{C}+{ }^{1}{ }^{1}$ Six file types are used or created by the SIT model: (1) *.DAT, (2) SIT.CFG, (3) SIT.PPP, (4) *.XYZ, (5) *.OUT, and (6) *.PRO files; these files are in ASCII format and can be viewed and edited in a DOS-based text editor (e.g., EDIT in MS-DOS version 5). The *.DAT, SIT.CFG, and SIT.PPP files are used by the SIT.EXE program to produce *.XYZ and *.OUT files; *.PRO files are created by the PROB.EXE program. The "*" symbol is a wildcard character that can be used to delineate files with the same extension in a directory. For example, the input file that contains the data from Lake Hart might be called HART.DAT. Output files generated on subsequent model executions would be called XHART.OUT, where $X$ $=a, b, c, \ldots, 8,9$.

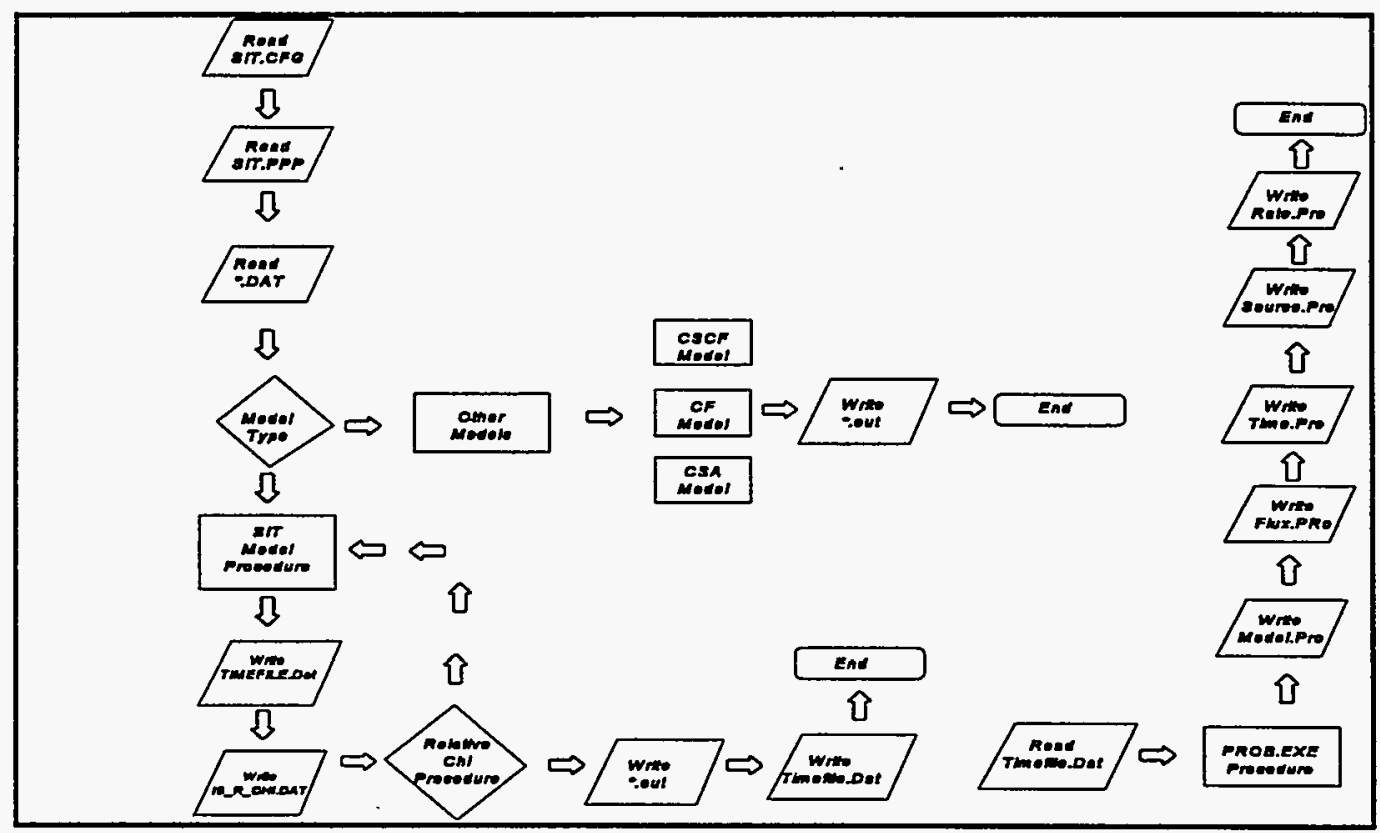

Figure 5-1. Generalized Flow of the SIT Simulation the program. 


\subsection{Input Files}

The purpose of the input files is to supply the model with the initial information needed to successfully execute the SIT.EXE program. The input files consist of three types: (1) data files $\left({ }^{*}\right.$.DAT), (2) a parameter file (SIT.PPP), and (3) a configuration file (SIT.CFG).

\subsubsection{Data files}

$\mathrm{A} *$.DAT file contains the depth profile of radionuclide activity (e.g., ${ }^{210} \mathrm{~Pb},{ }^{230} \mathrm{Th},{ }^{137} \mathrm{Cs}$ ) for a sediment core. These data are preceded by two lines of user-defined comments. The first comment line contains the title of the data and may be up to 30 characters in length. The second comment line is a user-friendly aid for reading the *.DAT file. This comment line identifies the columns in the data file in the following order: depth, isotope activity, dry bulk density (DBD), and the standard errors in the activities of the radionuclide measurements. Data units are not specifically defined in the SIT code. In the example *.DAT file provided in Figure 5-2, the authors elected to use the units of centimeters, disintegrations per minute, and grams. The user may elect to use other units; however, the same units must be used consistently in all program modules.

\begin{tabular}{|cccc|}
\hline & & & \\
Data Name & & & \\
Depth $(\mathrm{cm})$ & Data $(\mathrm{dpm} / \mathrm{g})$ & DBD $\left(\mathrm{cm}^{3} / \mathrm{g}\right)$ & Error $(\mathrm{dpm} / \mathrm{g})$ \\
0.73 & 1.58 & 0.544 & 0.38 \\
2.20 & 2.15 & 0.550 & 0.61 \\
3.42 & 1.65 & 0.524 & 0.49 \\
4.85 & 1.76 & 0.532 & 0.58 \\
6.22 & 1.89 & 0.511 & 0.43 \\
7.55 & 2.07 & 0.494 & 0.41 \\
8.86 & 1.75 & 0.489 & 0.56 \\
10.37 & 3.52 & 0.567 & 0.87 \\
11.89 & 3.08 & 0.565 & 0.87 \\
13.34 & 2.09 & 0.542 & 2.08 \\
14.85 & 2.97 & 0.561 & 0.76 \\
16.25 & 1.71 & 0.524 & 0.60 \\
17.63 & 1.73 & 0.515 & 0.52 \\
18.97 & 1.80 & 0.499 & 0.63 \\
20.21 & 0.66 & 0.465 & 0.52 \\
& & & \\
& & & \\
\hline
\end{tabular}

Figure 5-2. Example *.DAT File 


\subsubsection{SIT.PPP Parameter File}

The SIT.PPP file contains all the information required to run the SIT model. This parameter file serves two basic purposes: (1) the file contains information to direct the analysis of the data, and (2) the file identifies the type of output files to be generated during model execution. The SIT.PPP file is the most complicated portion of the SIT model, and the user must have a complete understanding of the parameter file to successfully execute the SIT model. A SIT.PPP file, with modified labels for each entry, is presented in Table 5-1.

The following is a detailed explanation of each line in the SIT.PPP file: ${ }^{2}$

\section{Line 1}

Entry 1 (number of iterations): The number of iterations used to adjust the coefficients $\left(a_{n}, b_{n}\right)$ for each set of parameter values $\left(P_{0}, V\right)$.

\section{Entry 2 (radionuclide [Am241, Be7, Be10, Cs137, Pa231, Pb210, Po210, Pu239, Pu240,} Ra226, Th230, and U234]): The radionuclide that is to be modeled. If any of the previous symbols are input by the user, the model will automatically choose the appropriate decay coefficient in units of $\mathrm{yr}^{-1}$. If the user would prefer to use a decay coefficient based on a different unit of time or to use an alternate radionuclide, that value can be input in line 1, entry 3 , of the SIT.PPP file.

Entry 3 (user t-1/2): The user-specified radionuclide half-life.

Entry 4 (time units): The user-specified time units (e.g., yr, sec, min, and months).

Entry 5 (activity units): The user-specified units of activity (e.g., dpm/g).

${ }^{2}$ Values may be entered in float, integer, or exponential format. 
Table 5-1. Example SIT.PPP File

\begin{tabular}{|c|c|c|c|c|c|c|}
\hline \multirow[t]{2}{*}{ Line 1} & $\begin{array}{r}\text { No. of } \cdots \\
\text { Iterations }\end{array}$ & $\begin{array}{l}\text { Radlonuclide } \\
\cdots\end{array}$ & $\begin{array}{l}\text { Usert-1/2 } \\
\therefore \therefore\end{array}$ & $\begin{array}{c}\text { Time unt } \\
\therefore\end{array}$ & $\begin{array}{c}\text { Activity Units } \$ \\
\vdots \\
\therefore\end{array}$ & \\
\hline & 10 & Pb210 & 26.22 & $\mathbf{y}$ & $\mathrm{dpm} / \mathrm{g}$ & \\
\hline \multirow[t]{2}{*}{ Line 2} & $\begin{array}{c}\text { Operational. } \\
\text { Mode }\end{array}$ & $\begin{array}{r}\text { Graphics } \\
-1 . . .\end{array}$ & $\therefore$ Spline & $\begin{array}{c}\text { Tension } \\
\text { Factor } \\
\text { F }\end{array}$ & & \\
\hline & 4 & On & Nospline & 10 & & \\
\hline \multirow[t]{2}{*}{ Line 3} & \# of Terms & $\begin{array}{c}\text { Contour file } \\
\ldots\end{array}$ & * of data poinis & $\begin{array}{l}\text { Starti } \\
\text { Deptr/Switch }\end{array}$ & $\begin{array}{l}\text { EndDepth } / \\
\text { start Depth }\end{array}$ & $\begin{array}{l}\text { Year Core Was } \\
\therefore \text { "Collected : }\end{array}$ \\
\hline & 2 & No & 16 & 0.0 & 35.0 & 1985 \\
\hline \multirow{2}{*}{ Line 4} & Surface $\left({ }^{*} / 4\right)$ & Fixed & Stant " & $\rightarrow$ End & $\therefore$ Step & \\
\hline & v & 14.0 & 13.0 & 17.0 & 0.5 & \\
\hline \multirow{2}{*}{ Line 5} & Fate ("/yr) & Fixed & Start & $\therefore$ End: & step & \\
\hline & v & 0.9 & 0.6 & 0.8 & 0.2 & \\
\hline \multirow{2}{*}{ Line 6} & Woight & Fixed & Start & End & Step & \\
\hline & $F$ & 0.0 & -0.9 & 0.9 & 0.1 & \\
\hline \multirow{2}{*}{ Line 7} & $\operatorname{Max} x^{2}$ & Time Prob & Rate Prob & "Source Prob & FiuxProb & Model Prob \\
\hline & 0.5 & $\mathbf{P}$ & $\mathbf{P}$ & $\mathbf{P}$ & $\mathbf{P}$ & $\mathbf{P}$ \\
\hline \multirow[t]{2}{*}{ Line 8} & Fit Criteria & $\begin{array}{l}\% \text { Errort } \\
\text { Data }\end{array}$ & $\begin{array}{c}\% \text { Error + Time } \\
\text { Markers }\end{array}$ & $\begin{array}{l}\text { Cutstep } \\
\because \therefore\end{array}$ & $\begin{array}{l}\text { Data for } \\
\text { PROBEXE }\end{array}$ & \\
\hline & 3 & 0 & 0 & 1 & TIMEFILE.DAT & \\
\hline \multirow[t]{2}{*}{ Line 9} & $\begin{array}{l}\text { Min Ago } \\
\text { Restriction }\end{array}$ & $\begin{array}{c}\text { Min Age (y) } \\
\vdots\end{array}$ & $\begin{array}{l}\text { MaxAge } \\
\text { Restriction }\end{array}$ & $\begin{array}{c}\text { Mex Age (yr) } \\
\therefore \\
\therefore\end{array}$ & & \\
\hline & No & 16.0 & No & 37.0 & & \\
\hline \multirow[t]{2}{*}{ Line 10} & $\begin{array}{c}\text { No. of Time } \\
\text { Markers }\end{array}$ & & & & & \\
\hline & 1 & & & & & \\
\hline \multirow{2}{*}{ Line 11} & Depth & $\operatorname{Tim} \theta$ & Error : & & & \\
\hline & 11.0 & 19.0 & 2.0 & & & \\
\hline
\end{tabular}

${ }^{\text {a }}$ The user must maintain consistency in the units. 
Entry 1 (operational mode [0-6]): The first entry is the operational switch: $0=$ Full-core SIT model [select full-core SIT with 0 terms (line 3, entry 1) to execute a CFCS model]; $3=$ Core sectioning with SIT model; $4=$ Full-core SIT model with probability data generated; $5=$ Constant Flux model; and $6=$ Constant Specific Activity model.

Entry 2 (graphics [on/off]): Graphics switch.

Entry 3 (spline [nospline/spline]): Spline smoothing of data.

Entry 4 (tension factor [1-100]): Spline tension factor.

\section{Line 3}

Entry 1 (number of terms [1-9]): Number of terms used in SIT model. Enter "10" when core cutting is to be tested using one, two, and three terms.

Entry 2 (contour file [Yes / No]): Option to create an *.XYZ file. The "no" switch will turn off all other restrictions to provide a complete file over the ranges of the parameters.

Entry 3 (no. of data points): Number of data points in the file.

Entry 4 (start depth switch [0/1]): Start location: 0 starts at the water interface; 1 starts at userspecified depth.

Entry 5 (end depth/start depth): If entry 4 was " 0 ," last data depth to be modeled. If entry 4 was " 1 ," the start location.

Entry 6 (year core was collected): The year the core was collected.

\section{Line 4: Surface Activity Parameter}

Entry 1 (surface [V/F]): Variable or fixed surface value. 
Entry 2 (fixed): If entry 1 was "F," the fixed surface value.

Entry 3 (start): Minimum surface value.

Entry 4 (end): Maximum surface value.

Entry 5 (step): Step size for surface value.

Line 5: Average Sediment Accumulation Rate Parameter

Entry 1 (rate [V/F]): Variable or fixed rate value.

Entry 2 (fixed): If entry 1 was "F", the fixed rate value.

Entry 3 (start): Minimum rate value.

Entry 4 (end): Maximum rate value.

Entry 5 (step): Step size for rate value.

\section{Line 6: Weight Parameter (-0.999 to 0.999 only)}

Entry 1 (weight [V/F]): Variable or fixed weight value.

Entry 2 (fixed): If entry 1 was " $F$," the fixed weight value.

Entry 3 (start): Minimum weight value.

Entry 4 (end): Maximum weight value.

Entry 5 (step): Step size for weight value.

\section{Line 7}

Entry $1\left(\max \chi^{2}\right)$ : Maximum allowable $\chi^{2}$ value (user specified). 
Entries 2 -5 (switches for writing probability data to TIMEFILE.DAT [NP/P] $]^{3}$ ): "NP" will not write data to TIMEFILE.DAT; "P" will write data to TIMEFILE.DAT. The switches are placed in the following order: time, rate, source, flux, and model.

\section{Line 8}

Entry 1 (fit criteria [0-3]): Fit criteria switch: $0=$ model must fit within the error bars for each data point; $2=$ model must fit within the average error for the total data profile; $3=$ no restriction of fit other than $\max \chi^{2}$.

Entry 2 (\% error + data [1-99]): This entry allows the user to add an additional percentage of error to the data when restricted fit criteria are used (line 8 , entry: 0 or 2).

Entry 3 (\% error + time markers [1-99]): This entry allows the user to add additional error to the time markers.

Entry 4 (cut step [1-10]): This is the number of data points the model will progress through during core cutting. For example, if the user would like to model every second data point with core cutting, a " 2 " would be entered here.

Entry 5 (data for PROB.EXE): The file name for the probability data to be written by PROB.EXE (normally left at the default, TIMEFILE.DAT).

\section{Line 9: Core Age Restrictions}

Entry 1 (minimum age restriction [Yes/No]): A restriction on the minimum age of the bottom of the core.

Entry 2 (min age): If entry 1 was "yes," then user-specified minimum age.

Entry 3 (maximum age restriction [Yes/No]): A restriction on the maximum age of the core.

Entry 4 (max age): If entry 3 was "yes," enter the user-specified maximum age of the core; if

${ }^{3}$ Probability data can be written only if the operational model selected in line 2 , entry 1 , is the full-core SIT model with probability data (mode 4). 
entry 3 was "no," the SIT model will default to six times the half-life of the model isotope.

\section{Line 10}

Entry 1 (no. of time markers): The number (integer) of time markers in the core.

\section{Line 11 Through Last Line in File 4}

Entry 1 (depth): Depth of time marker.

Entry 2 (age): Age of time marker.

Entry 3 (error): Error in age of time marker.

\subsubsection{SIT.CFG Configuration File}

The purpose of the configuration file is to inform the SIT model of the last data file name that was modeled and the number of the current iteration. The SIT.CFG file is created when the SIT.EXE program is executed for the first time. SIT.EXE has the ability to save up to 36 different modeled outputs of the same data. Model outputs are differentiated by an alphanumeric character $(a, b, c, \ldots, 8,9,0)$ appended to the beginning of the *.OUT and *.XYZ files. For example, the Hart.dat input file can produce output files designated aHART.OUT, bHART.OUT, cHART.OUT, dHART.OUT, ..., 8HART.OUT, 9HART.OUT, and OHART.OUT. If the user runs the SIT.EXE program more than 36 times without changing the data file, the program will begin to overwrite the earlier model outputs. The SIT.EXE program will ask if you would like to change the data file (Y/N). If " $\mathrm{Y}$ " is chosen, the new data file name is entered (remember to change the SIT.PPP if there are any differences in the data, otherwise the model will crash). If " $\mathrm{N}$ " is selected, the model will continue from the last saved value in SIT.CFG. The user may wish to start the modeling sequence over by simply choosing the yes option and retyping the same file name, this will restart the SIT.CFG back at the initial "a*.*" position.

${ }^{4}$ Use a separate line for each time marker. 


\subsection{SIT.EXE Program}

The SIT.EXE program controls the execution of the SIT model. This program retrieves initial information from the input files, performs model calculations, and stores the results in the appropriate output file. Once all program files have been copied to a computer subdirectory, a model run is initiated by typing "SIT" followed by the ENTER key (see Section 5.3.1.). If the graphics switch line 2 , entry 2 , is set to "on," the best $\chi^{2}$ model up to that point in program execution is displayed in graphic form on the screen; if the graphics switch is set to "off" only the best $\chi^{2}$ value is displayed.

\subsubsection{SIT.EXE Execution}

The SIT program is executed from the directory that contains the SIT.PPP and SIT.CFG files, the SIT.EXE program, and the respective input data file. For easy setup and execution, a separate directory should be established under the root directory ( C:ISIT). The *.OUT, *.XYZ, IS_R_CHI.DAT, and TIMEFILE.DAT files are created during execution of the SIT program. The user may use a batch file to run the SIT.EXE and PROB.EXE programs. An example of a batch file is presented in Figure 5-3.

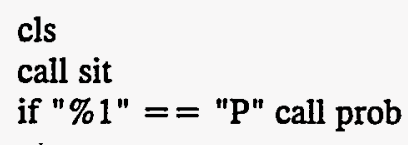

Figure 5-3. Example Batch File

\subsubsection{Output Files}

The output files are created in ASCII format during program execution. The SIT model creates the following four output files when the model is executed: *.OUT files, ${ }^{*}$.XYZ files, IS_R_CHI.DAT file, and TIMEFILE.DAT file. These files are designed to allow the user to interpret the results generated by the model. These files can be viewed using a standard DOSbased text editor. 


\subsubsection{1 *.OUT Output Files}

The *.OUT files contain information on the input parameters, modeled isotope, abbreviated results from each successful iteration, and the best results based on the relative $\chi^{2}$ procedure. As *.OUT files are generated, up to 36 runs can be saved without overwriting the files. An alpha or numeric character is appended to the front of the file that is being generated (see Section 5.2.3). The *.OUT files are organized in a manner that allows the user to easily retrieve information from the files. The first line in an *.OUT file identifies the data title that is specified in the first line of the corresponding *.DAT file. The second line identifies the date and time of the model run. The third line identifies the name and location of the corresponding *.DAT file. The next section of the file displays the parameters that were used to create the model (line 1 through line 9 of the SIT.PPP file), followed by the linear search outputs. This section presents each of the model solutions in an abbreviated format. Figure 5.4 illustrates the linear search output:

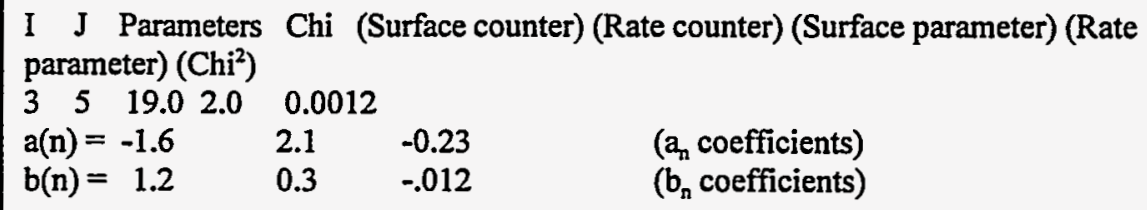

Figure 5-4. Example of Linear Search Output

The last segment of an *.OUT file displays the best answer calculated from the relative $\chi^{2}$ procedure. The $a_{n}, b_{n}, \chi^{2}$, and best parameters are displayed followed by the results for the best model. The information is presented in column format. Items that appear in the output are, from left to right, depth, age, time, rate, source, flux, data activity, and model activity.

\subsubsection{2 *.XYZ Output Files}

The *.XYZ files store the best model result (contained at the end of the *.OUT files) in a format that can be imported into other computer applications to generate two-dimensional graphical displays of program results. 


\subsubsection{IS_R_CHI.DAT Output File}

The IS_R_CHI.DAT file contains four columns of data that can be used to create threedimensional or contour plots of the SIT model linear search results. This file is in ASCII format and can easily be imported into several plotting programs.

\subsubsection{TIMEFILE.DAT Output File}

The TIMEFILE.DAT file is created by the SIT model and is the input file for the PROB.EXE program. This file should not be edited before execution of the PROB.EXE program.

\subsection{PROB.EXE Program}

The PROB.EXE program computes statistical parameters on the data produced by the SIT model. Simpson's rule is used to calculate an expected average $E_{1}(T)$ and the variance $\sigma(T)^{2}$ around the average. Accordingly,

$$
E_{1}(T)=\frac{1}{3}\left(T_{\min }+T_{\max }+T_{\text {midpoint }}\right)
$$

and

$$
\sigma(T)^{2}=\left[E_{2}(T)-E_{1}(T)^{2}\right]
$$

may be calculated as

$$
=\frac{1}{18}\left(\left[T_{\text {midpoint }}-\frac{1}{2}\left(T_{\max }+T_{\min }\right)\right]^{2}+\frac{3}{4}\left(T_{\max }+T_{\min }\right)^{2}\right)
$$

For a distribution that is cumulatively log-normally distributed or approximately so (Feller 1957), the cumulative probability of 68-percent $[\mathrm{P}(68)]$ occurs at $E_{1}(T)$, the 16-percent $[\mathrm{P}(16)]$ at $E_{1}(T)\left(1+\sigma^{2} / E_{1}(T)^{2}\right)^{-3 / 2}<E_{1}(T)$, and the 84-percent $[\mathrm{P}(84)]$ at $E_{1}(T) \exp \left[\left(\ln \left(1+\sigma^{2} / E_{1}(T)^{2}\right)^{-1 / 2}\right]>\right.$ $E_{1}(T)$. A log-probability graph can then be made and the 10-percent $[\mathrm{P}(10)]$ and the 90 -percent $\mathrm{P}(90)$ values read. The distribution at each depth is then taken to be represented by the expected 
average value at $P(68)$, with uncertainty around the $P(68)$ value described through the $P(10)$ and $\mathrm{P}(90)$ values. These values then can be used in plotting the error uncertainty of the time-todepth, rate-to-depth, source-to-depth, isotopic flux-to-depth, and model activity-to-depth profiles. The output results are found in the TIME.PRO, RATE.PRO, SOURCE.PRO, FLUX.PRO, and MODEL.PRO files.

\subsubsection{PROB.EXE Execution}

Before executing the PROB.EXE program, a TIMEFILE.DAT file must be created by the SIT.EXE program (see Section 5.2.2). The TIMEFILE.DAT file is the input file for the PROB.EXE program. On the basis of the number of options that were selected.for probability data (line 7, entries 2 through 5, in the SIT.PPP file), the PROB.EXE program will create the appropriate *.PRO files.

\subsection{2 *.PRO Output Files}

The PROB.EXE program creates files with a "PRO" extension. The PROB.EXE program is capable of creating *.PRO files for time, rate, source, flux, and model activity. The *.PRO files include values for depth, $\min$, $\max , \mathrm{P}(68), \mathrm{P}(90), \mathrm{P}(10), \mathrm{P}(90)-\mathrm{P}(68), \mathrm{P}(68)-\mathrm{P}(10)$, volatility, risk, and relative risk. If insufficient data are available to complete a probability density function (i.e., less then 10 models), the PROB.EXE program will display simple descriptive statistics including the mean and standard deviation for time, rate, source, flux, and model activity.

\subsection{SIT Model Usage}

\subsection{Introduction and Use of the SIT Code}

The SIT model uses two basic steps to solve a problem. First, the problem must be formulated in terms that the model can use, such as isotope activity, density corrected depth, and historical time markers. Second, the computer code is run and the results processed for analysis. The computer run is completed through input of data collected from a core and through model operations that have been mapped out in the SIT.PPP parameter file. After a successful simulation has been completed, the user may choose to execute the PROB.EXE program to calculate probability density functions (see Section 5.4) from the results of the SIT.EXE program execution. 


\subsection{Problem Formulation}

Application of the SIT model to a specific problem requires the problem to be formulated in terms that the SIT model can interpret. Problem formulation entails (1) identifying spatial and temporal domains of influence for the location of core collection, (2) analyzing the sedimentary structure of the core, (3) analyzing the isotope activity of the core, (4) and identifying time markers that can be used to constrain the model results. Once the necessary data have been acquired and a general understanding of the area under investigation has been achieved, the appropriate program control options must be specified within the SIT.PPP parameter file.

\subsection{Data Format}

All the files used by the SIT model are in ASCII format. The specific isotopic depth distributions and the sediment DBD are entered in the *.DAT file in the format described in Section 5.2.1. The information on the time markers and sedimentation rates as well as the statistical error allowed for the model must be entered in the SIT.PPP parameter file to run a simulation. Error factors and restraining environmental factors must also be identified in the SIT.PPP parameter file. The SIT model will arrive at a solution quicker if the sedimentation rate and the presence of bioturbation and sediment disturbances of the area are approximately known.

\subsection{Model Operation}

The SIT model is designed to run on a IBM-compatible computer with an MS-DOS version 5.0 or comparable operating system. The use of a text editor is essential for editing the files that control the models and for viewing the output files. The procedures discussed in the following subsections assume the use of an IBM-compatible 486/50-megahertz (MHZ) computer running MS-DOS, version 5.0, with 8 megabytes of available RAM.

\subsubsection{Full-Core Linear Search}

The most commonly used capability of the SIT model is the full-core linear search. The procedure steps through the parameters of surface activity and sedimentation rate with a userspecified range and step size. All data points are used to obtain a model of the radionuclide activity, and every data point is included in the fit criteria for the model acceptance. 
The first step for performing a full-core linear search is to create a data file in the format explained in Section 5.2.1. The second step is to edit the SIT.PPP file to run the created data file (see Section 5.2.2). To run a full-core model, the operational mode (line 2, entry 1, of the SIT.PPP file) must be "0". The remaining lines and entries in the SIT.PPP file are set up as needed for specific uses (see Section 5.2.2). After saving the *.DAT file and the SIT.PPP file, the model is executed by typing "SIT" and by pressing the RETURN key. The program will prompt for a change in the data file name. The user selects "Y" and then types in the desired file name and presses the ENTER key. The program displays the solution on the screen. At the end of the simulation, the best answer based on the $\chi^{2}$ fit and the time markers is printed to the *.OUT file. The *.XYZ file will contain an ASCII file that may be imported into a graphics program for further data analysis. By striking any key, the user can stop the program execution at any point during the simulation. The user can then go back to the SIT.PPP file and make any changes that are necessary to improve the solution and run the model again. If the user declines to change the data file name (by typing " $\mathrm{N}$ " at the prompt), the program will store the new output file using the same file name but with a new alpha or numeric character prefix to avoid overwriting the previous solution (see Section 5.3.2.1).

\subsubsection{Core Cutting}

The SIT model is capable of producing models based on cutting the core to a desired length, starting at a depth below the surface, or stopping the simulation before reaching the bottom of the core. The procedure for creating the data file is the same procedure that is used in the full core linear search; however, the following changes should be implemented in the SIT.PPP parameter file.

Line 1: Set up as needed depending on the core.

Line 2, Entry 1: Set to "3" for a core-sectioning model.

Line 3, Entry 1: Identify the number of terms to be used during the core cutting or enter "10." An entry of " 10 " will run the core-cutting procedure over one, two, and three terms at the userspecified cut interval (line 8, entry 4).

Line 3, Entry 2: Enter "No"; this option should be always set to "No" when running the corecutting procedure. 
Line 3, Entry 3: Set to the number of data points in the file.

Line 3, Entry 4: Specify the start position of the core (see Section 5.2.2).

Line 3, Entry 5: Specify the bottom depth of the core.

The remainder of the file is set up based on the specific core (see Section 5.2.2)

Note: To stop the model during the multiple-term core cutting procedure, use the Esc key only.

\subsubsection{Probability Density Output}

To generate the probability density output of a model core, the operational mode (line 2 , entry 1 ) must be set to "4" and the time, rate, source, flux, and model switches (line 7, enties 2 through 5) must be set either to "NP" (no probability density) or P (probability density output)(see Section 5.2.2). The other parameters in the SIT.PPP file are set up as needed for the specific core. After the SIT model run is completed, the PROB.EXE program may be run to calculate the probability density functions of the output. Type "PROB" to execute the program. The PROB.EXE program will prompt for an input file name; type the file name that contains the data, which is usually the TIMEFILE.DAT file(line 8, entry 5).

\subsubsection{Alternative Models}

The SIT model offers three alternative models for the calculation of the time-to-depth distribution of a sediment core: the CF model, CFCS model, and the CSA model (see Section 2.2). These models are executed from the SIT.PPP parameter file with the proper input in line 2 , entry 1 . 


\subsection{Example Simulations}

Three examples are provided in this section to illustrate how various SIT options work. These examples illustrate the use of the SIT model to characterize (1) a constant sedimentation accumulation rate/constant isotopic flux synthetic profile using ${ }^{210} \mathrm{~Pb},(2)$ a variable sediment accumulation /variable flux profile using ${ }^{210} \mathrm{~Pb}$, and (3) a preliminary demonstration of the corecutting procedure. The example simulations discussed in the following subsections were performed using an IBM-compatible 486/50-MHz computer running MS-DOS version 5.0, with 8 megabytes of available RAM.

\subsection{Example 1: Constant Sediment Accumulation Rate/Constant Isotopic Flux}

One method of verifying that the model is operating properly is to examine a synthetic profile that does not exhibit any complex variations in sedimentation rates or isotopic flux. The profile is created by picking an arbitrary surface activity, then picking any sedimentation rate for one of the standard radionuclides, and then calculating an activity-to-depth profile using equation (1-2).

\subsubsection{Execution of Example 1}

For this example, the surface activity is $20.00 \mathrm{dpm} / \mathrm{g}$ of ${ }^{210} \mathrm{~Pb}$ (half-life $=22.26 \mathrm{yr}$ ) and the sediment accumulation rate is $1.00 \mathrm{~cm} / \mathrm{yr}$. A constant DBD of $0.89 \mathrm{~g} / \mathrm{cm}^{3}$ is assumed for this example. This profile may be modeled using the CFCS model. The SIT.PPP file is set up to run the CFCS model by placing a zero in line 3 , entry 1 (see Section 5.2.2). The surface-activity search range is entered in the SIT.PPP file as required to cover the characteristics of the profile (see Appendix A). When using a CFCS model, the model will solve for the slope of the decay curve and will calculate a sedimentation rate based on the isotope modeled. When the model execution is completed, the results may be viewed in EX1.OUT and EX1.XYZ files (see Appendix A). The EX1.XYZ file is then plotted in a graphics program to view the results of the model (see Figure 7-1). When using the CFCS model, no probability data are produced from the SIT.EXE program. 

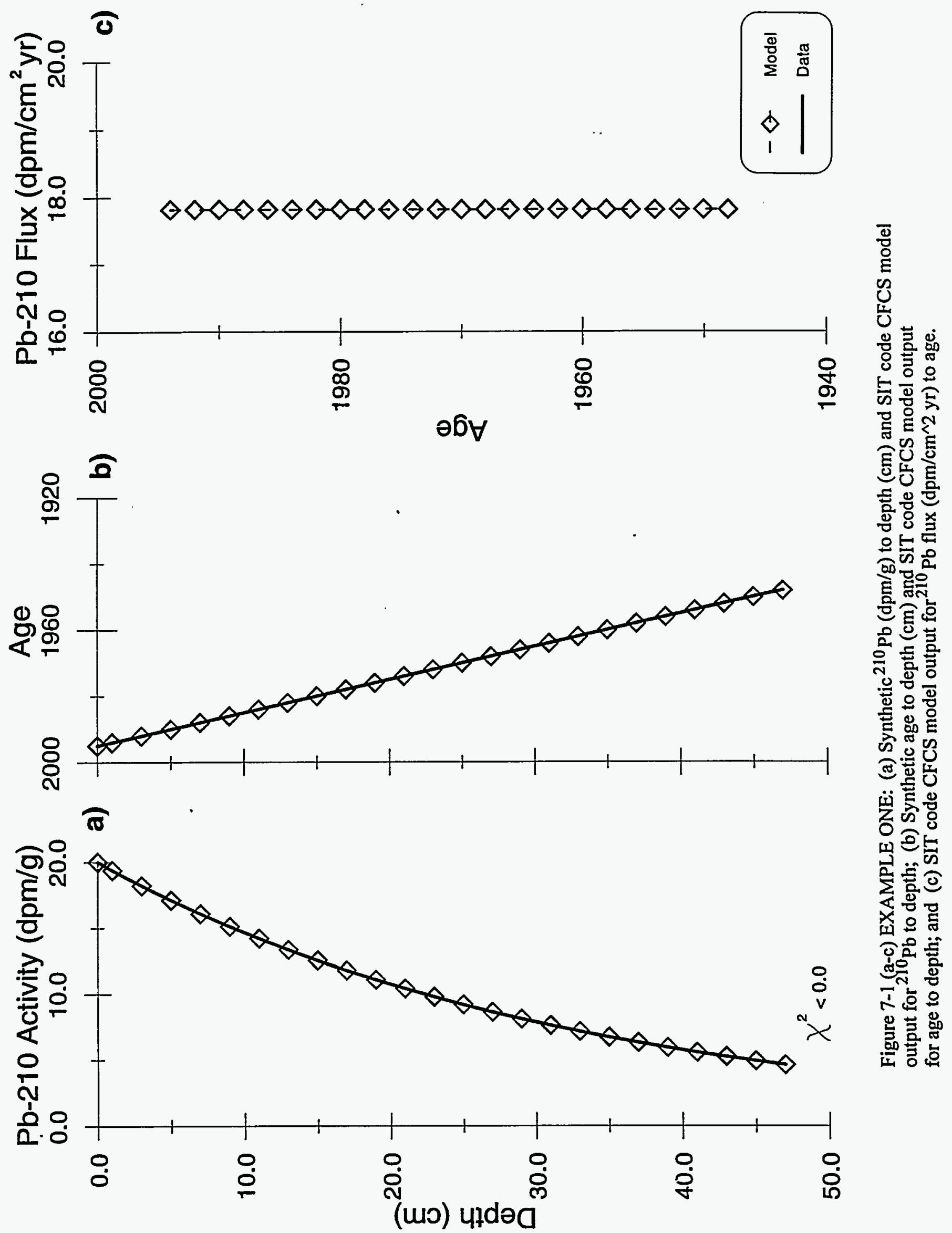


\subsubsection{Results of Example 1}

Figure 7-1 illustrates the results obtained with the SIT model for the CFCS simulation. The output from this simulation may be found in Appendix A along with the input files used to generate the results. This simulation required 0.02 hour of processing time.

\subsection{Example 2: Variable Sediment Accumulation Rate/Variable Flux Rate}

In the natural environment, complex isotopic profiles are common; the SIT model was designed for these types of profiles. The profile used in this demonstration is from a sediment core collected in a pond. The profile demonstrates an elevated area of ${ }^{210} \mathrm{~Pb}$ activity at a depth of 12.5 $\mathrm{cm}$ (see Figure 7-2). A two-term model simulates this type of profile best. Two time markers are available to restrict the model: (1) a peak in ${ }^{137} \mathrm{Cs}$ at $11.9 \mathrm{~cm}$, which is related to the 1963 fallout from nuclear weapons testing (Ritchie and McHenery 1990); and (2) the pond was created in 1922 therefore the sediments may not be older than 1922 .

\subsubsection{Execution of Example 2}

The most important step in this simulation is the proper set up of the SIT.PPP parameter file, which is summarized as follows:.

- Line 1 is set up for the use of ${ }^{210} \mathrm{~Pb}$ in units of disintegrations per minute per gram $(\mathrm{dpm} / \mathrm{g})$.

- Line 2, entry 1 , is set to "4"; this operational mode will generate the probability density data needed by the PROB.EXE program to complete the statistical analysis (see Section 5.2.2).

- Line 3, entry 1 , is set to "2" for two terms; the remainder of line 3 is set up as dictated by the characteristics of the core.

- Lines 4 through 6 are set up for the desired search ranges and step sizes.

- Line 7, entry 1 , is the maximum allowable $\chi^{2}$ entry; for this example, all solutions to the profile will be accepted if $\chi^{2}$ is below $(0.5 \mathrm{dpm} / \mathrm{g})^{2}$. The remainder of line 7 activates the 


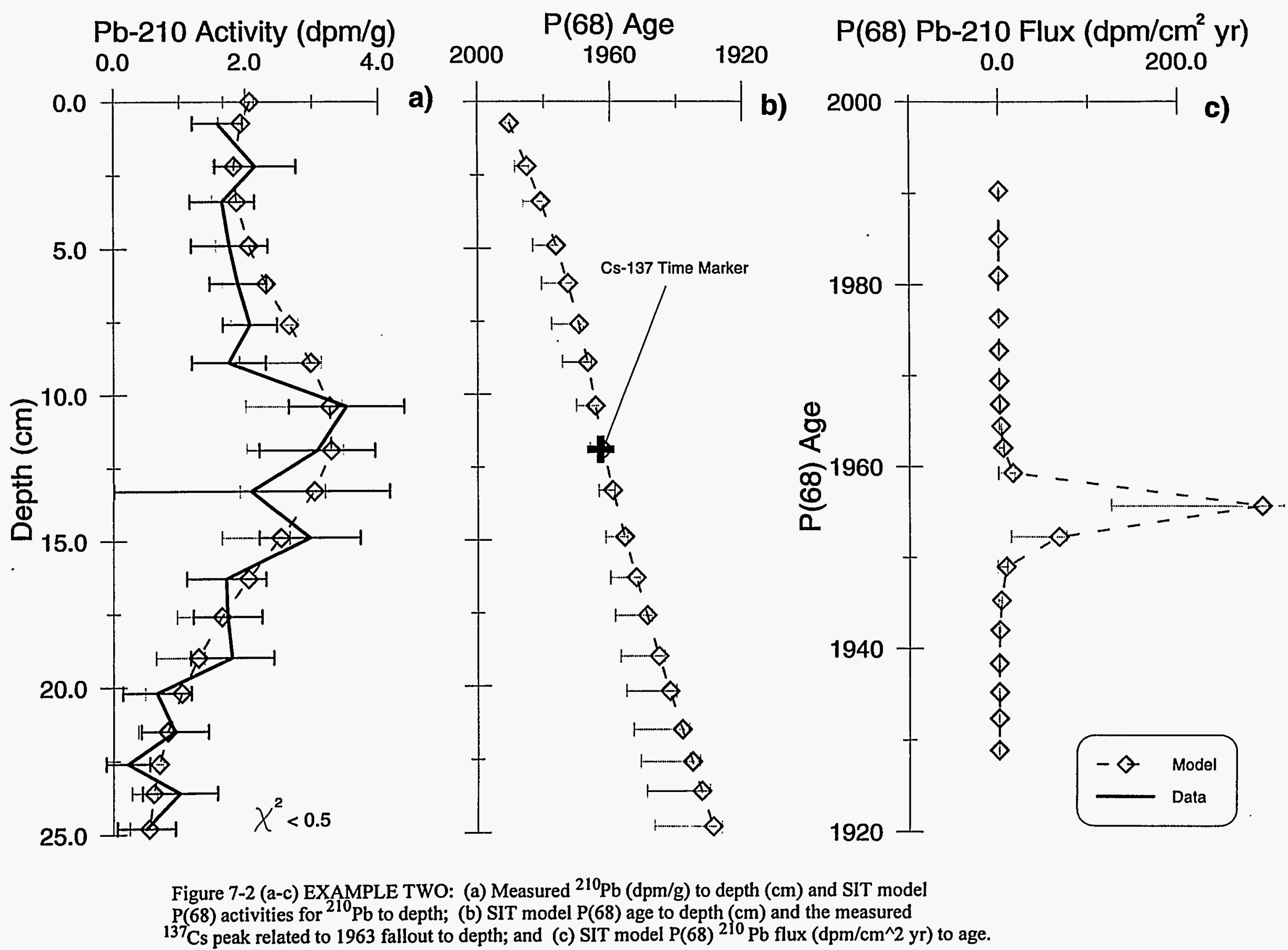


specific probability density outputs (see Section 5.2.2). For this example, all of the probability density data are saved to the data file TIMEFILE.DAT (Appendix A).

- Line 8 is set up to accept all answers having an error term with no added percent error required. The file where the probability density data are to be stored is the TMMEILE.DAT file (see Section 5.3.2.4).

- Line 9, entry 3, is set to "yes," and entry 4 is set to "71.0" to limit the bottom age of the sediments.

- Line 10 , entry 1 , indicates there is one time marker that will be used in the simulation.

- Line 11 is set up with the depth and time plus error for the ${ }^{137} \mathrm{Cs}$ time marker.

The example SIT.PPP parameter file for the example 2 run is presented in Appendix A.

To run the simulation, execute the SIT.EXE program by typing "sit" at the DOS prompt. At the conclusion of the program, execute PROB.EXE by typing "PROB" at the DOS prompt. The PROB.EXE program will calculate the probability density distributions for each of the parameters in example 2 and will write the *.PRO files containing the ASCII solutions that can be edited in a DOS-based text editor.

\subsubsection{Results of Example 2}

The results of the example 2 simulation are listed in Appendix A. These listings include AEX2.OUT, TIME.PRO, RATE.PRO, SOURCE.PRO, FLUX.PRO, and MODEL.PRO.

Seventeen models for the core were accepted for use in the probability density calculations on the basis of the fit criteria and maximum $\chi^{2}$. Probability distributions were calculated for each depth for each parameter (i.e., the time distribution at a depth of $11.9 \mathrm{~cm}$ will be composed of 17 values). The results of the simulation are presented in Figure 7-2. The original activity data plus the analytical error are plotted against the SIT-generated $P(68)$ activity values at each depth, and the $P(10)$ and $P(90)$ statistical limits are shown. The example 2 simulation required 0.04 hour of processing time. 


\subsection{Example 3: Introductory Use of Core Cutting}

Example 3 demonstrates the core-cutting capabilities of the SIT model. The SIT model allows the user to start the simulations at a minimum depth and then to add points based on the cut interval defined in line 8, entry 4, of the SIT.PPP parameter file (see Section 5.2.2). The SIT model will run a simulation at each of the cut-interval depths and will search the depth range based on the surface activity parameters and the average sediment accumulation rate parameters. The best answer is based on the best relative $\chi^{2}$ if a time marker is used or is based solely on the $\chi^{2}$ fit if there are no time markers. The best models for each of the cut intervals are compared to produce a final best model for the simulation.

\subsubsection{Execution of Example 3}

For core cutting, the SIT.PPP parameter file is set up in the same manner as in examples 1 and 2. The only changes in the file setup are in the operational switches (line 2, entry 1), and the cut interval (line 8, entry 4) (see Section 5.2.2 and Section 6.4.2, respectively). No probability density data can be generated during the core cutting procedure; therefore, the switches in line 7 need to be set to "NP" to indicate no probability. Appendix A presents the SIT.PPP parameter file that was used in the example 3 simulation.

\subsubsection{Results of Example 3}

The SIT results of example 3 are listed in Appendix A and include the AEX3.OUT output file. Taking into account the time marker, the SIT model chose the best answer with the core cut at the 17.5-cm depth. The model fit to the data is within the parameters set up in the SIT.PPP parameter file (see Appendix A). The SIT model generates an age-to-depth profile as well as a rate-to-age profile for the first $17.5 \mathrm{~cm}$ of the core (see Figure 7-3). The example 3 simulation required 0.03 hour of processing time. 

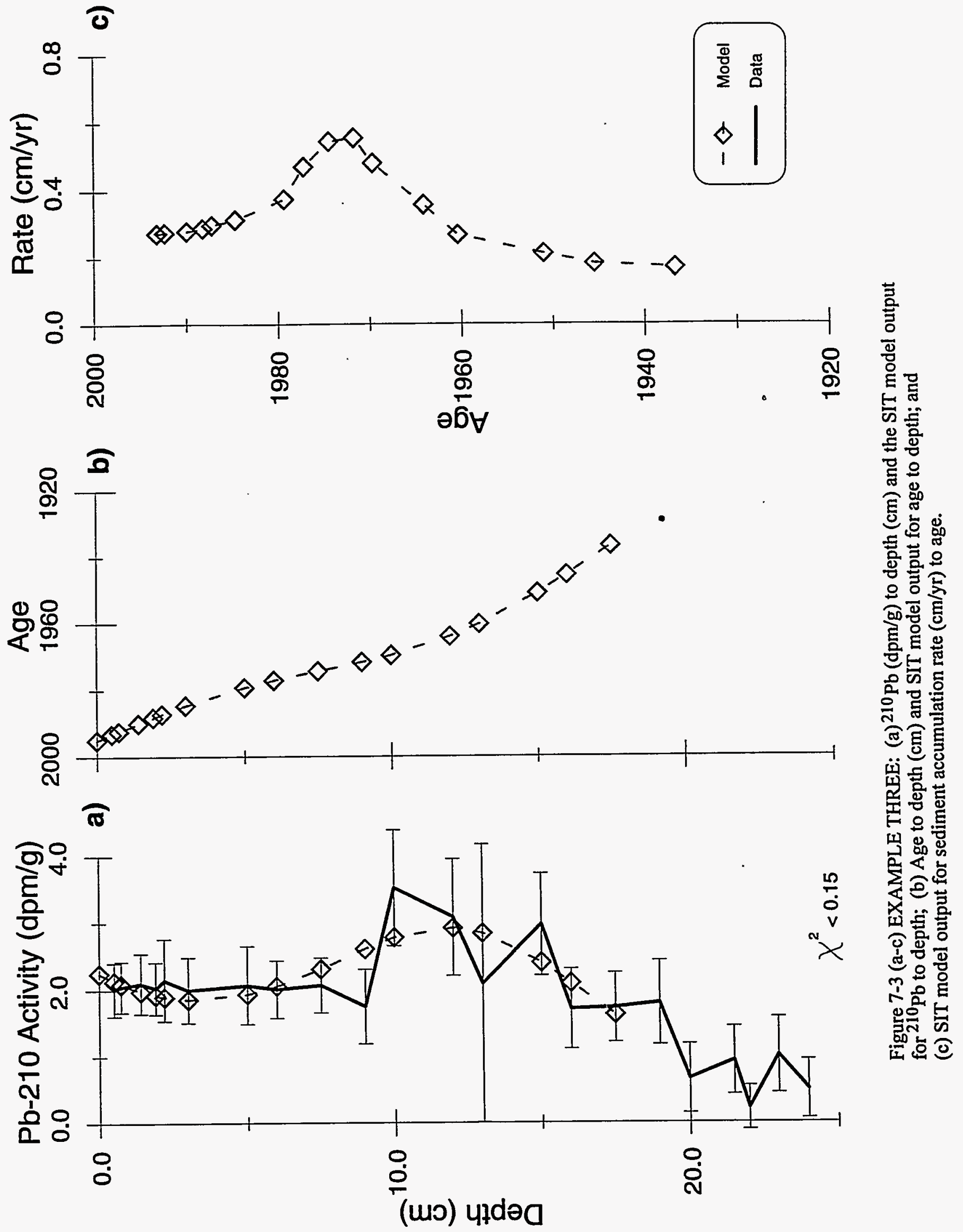


\subsection{Conclusions}

The SIT model has been developed as an MS-DOS-based computer software program to analyze complex depth profiles of radioisotope activity measured in marine and freshwater sediment cores. The model is designed to reconstruct the history of unmixed sediment deposition and to recover past events, such as human impacts and natural chemical alterations, that are preserved in buried sediments. The approach, based on the SIT model, applies inverse numerical analysis techniques to disentangle components of variations in radioisotope activity with sediment depth caused by variations in sediment accumulation rate and radioisotope flux. This report is a user's guide for the SIT model that includes the basis for the conceptual model and its numerical implementation, simulations using sample data sets, and the input and output listings from these simulations; a 3.5 inch diskette containing the software for the SIT model is provided in a pocket on the inside back cover of this report.

\subsection{Acknowledgment}

This research was funded by a grant from the U.S. Department of Energy (DOE) Ocean Margins Program under Contract No. DE-AC04-94AL96907. Additional funding was received from the DOE Grand Junction Projects Office (GJPO) Program Support Research and Development Program and from the Industrial Associates of the Basin Modeling Group at the University of South Carolina in Columbia, South Carolina. Assistance is gratefully acknowledged for the help provided during portions of this project by the following individuals: Dr. Steve Kuehl, School of Marine Science of the Virginia Institute of Marine Science at the College of William and Mary; Mr. David Dukat, formerly of the University of South Carolina Radiocarbon Dating Laboratory; and Mr. Mark Hollenbach, Ms. Kathleen Dixon, Mr. Darrel McKay, and Mr. Darrin Cisar of Rust Geotech, operating contractor for DOE-GJPO in Grand Junction, Colorado. 


\subsection{References}

Appleby, P.G., and F. Oldfield, 1978. "The calculation of Lead-210 dates assuming a constant rate of supply of unsupported Lead-210 to the sediment." Catena, 5, 1-8.

Bendat, J.S., and A.G. Piersol, 1971. Random Data: Analysis \& Measurement Procedures. Wiley-Interscience, NY.

Benninger, L.K., R.C. Aller, J.K. Cochran, and K.K. Turekian, 1979. "Effects of biological mixing on the ${ }^{210} \mathrm{~Pb}$ chronology and trace metal distribution in a Long Island Sound sediment core." Earth Planet. Sci. Lett., 43, 241-259.

Carroll, J.L., and I. Lerche, 1990. "A cautionary note on the use of ${ }^{87} \mathrm{Sr} /{ }^{86} \mathrm{Sr}$ sediment ages in stratigraphy studies." Nucl. Geophys., 4, 461-466.

Carroll, J.L., and I. Lerche, 1991. "Determining resolution for ${ }^{87} \mathrm{Sr} /{ }^{86} \mathrm{Sr}$ profiles in marine sediments." Nucl. Geophys., 33, 119-129.

Carroll, J.L., I. Lerche, J.D. Abraham, and D.J. Cisar, 1995. "Model-Determined Sediment Ages from ${ }^{210} \mathrm{~Pb}$ Profiles in Un-mixed Sediments." Nucl. Geophys., 9, 553-565.

Carroll, J.L., I. Lerche, J.D. Abraham, and D.J. Cisar, 1996. "Sediment ages and flux variations from depth profiles of radioisotopes: lake and marine examples." Limnol. Oceanogr. (submitted).

Chanton, J.P., C.S. Martens, and G.W. Kipphut, 1989. "Lead-210 sediment geochronology in a changing coastal environment." Geochim. Cosmochim. Acta, 47, 1791-1804.

Christensen, E.R., 1982. "A model for radionuclides in sediments influenced by mixing and compaction." J. Geophys. Res., 87, 566-572.

DeMaster, D.J., and J.K. Cochran, 1982."Particle mixing rates in deep-sea sediments determined from excess ${ }^{210} \mathrm{~Pb}$ and ${ }^{32} \mathrm{Si}$ profiles.” Earth Planet. Sci. Lett., 61, 257-271. 
Feller, W., 1957, An Introduction to Probability Theory and Its Applications, vol. 1, John Wiley and Sons, New York, 461 pps.

Gardner, L.R., P.Sharma, and W.S. Moore, 1987. "A regeneration model for the effect of bioturbation by fiddler crabs on ${ }^{210} \mathrm{~Pb}$ profiles in salt marsh sediments." $J$. Environ. Radioactivity 5, 25-36.

Goldberg, E.D., 1963. “Geochronology with ${ }^{210} \mathrm{~Pb}$.” In: Radioactive Dating, I.A.E.A., Vienna. pp.121-131.

Goldberg, E.D., and K. Bruland, 1974. "Radioactive Geochronologies." In: The Sea, Volume 5: Marine Chemistry (ed. E.D. Goldberg). Wiley-Interscience, NY.

Goldberg, E.D., and M. Koide, 1962. "Geochronological studies of deep-sea sediments by the Io/Th method." Geochim. Cosmochim. Acta, 26, 417-450.

Goldberg, E.D., V. Hodge, M. Koide, J. Griffin, O.P. Bricker, G. Matisoff, G.R. Holdren, and R. Braun, 1978. "A pollution history of Chesapeake Bay." Geochim. Cosmochim. Acta, 42,14131425.

Koide, M., A. Soutar, and E.D. Goldberg, 1972. "Marine Geochronology with ${ }^{210} \mathrm{~Pb}$." Earth Planet. Sci. Lett., 14, 442-446.

Koide, M., K.W. Bruland and E.D. Goldberg, 1973. “228 $\mathrm{Th} /{ }^{232} \mathrm{Th}$ and ${ }^{210} \mathrm{~Pb}$ geochronologies in marine and lake sediments." Geochim. Cosmochim. Acta, 37, 1171-1187.

Kuehl, S.A., D.J. DeMaster, and C.A. Nittrouer, 1986. "Nature of sediment accumulation on the Amazon continental shelf." J. Cont. Shelf Res., 6, 209-225.

Liu, J., J.L. Carroll, and I. Lerche, 1991. "A technique for disentangling temporal source and sediment variations from radioactive isotope measurements with depth." Nucl. Geophys., 5, 3145.

Menke, W., 1984. Geophysical Data Analysis: Discrete Inverse Methods, Academic Press, Orlando. 
Nittrouer, C.A., D.J. DeMaster, B.A. McKee, N.H. Cutshall, and I.L. Larsen, 1983. "The effect of sediment mixing on ${ }^{210} \mathrm{~Pb}$ accumulation rates for the Washington continental shelf." Mar. Geol., 54, 201-221.

Officer, C.B., 1982. "Mixing, sedimentation rates and age dating for sediment cores." Mar. Geol., 46, 261-278.

Ritchie, J.C., and R. McHenry, 1990. "Application of Radioactive Fallout Cesium-137 for Measuring Soil Erosion and Sediment Accumulation Rates and Patterns: A Review." J. Environ. Qual. 19, 215-233.

Robbins, J.A., 1978. "Geochemical and geophysical applications of radioactive lead isotopes." In: Biogeochemistry of Lead (ed. J. P. Nriago) Elsevier, North Holland, p. 285-393.

Smith, J.N., and A. Walton, 1980. "Sediment accumulation rates and geochronologies measured in the Saguenay Fjord using the ${ }^{210} \mathrm{~Pb}$ dating method." Geochim. Cosmochim. Acta, 44, 225-240.

Tolstov, G.P., 1962. Fourier Series. Dover Publications, NY.

Waugh, W.J., J. Carroll, J.D. Abraham, and D.S. Landeen, 1996. “Applications of dendrocronology and sediment geochronology to establish reference episodes for evaluation of environmental radioactivity." J. Eviron. Rad., (submitted) 


\section{Appendix A}

Input and Output Listings From Example Simulations 


\section{Example 1: Data File EX1.DAT}

Example one

Depth(cm) Data(dpm/g) DBD $\left(\mathrm{g} / \mathrm{cm}^{3}\right)$ error $(\mathrm{dpm} / \mathrm{g})$

$\begin{array}{llll}1 & 19.39 & 0.89 & 0.01 \\ 3 & 18.22 & 0.89 & 0.01 \\ 5 & 17.12 & 0.89 & 0.01 \\ 7 & 16.09 & 0.89 & 0.01 \\ 9 & 15.12 & 0.89 & 0.01 \\ 11 & 14.21 & 0.89 & 0.01 \\ 13 & 13.35 & 0.89 & 0.01 \\ 15 & 12.54 & 0.89 & 0.01 \\ 17 & 11.79 & 0.89 & 0.01 \\ 19 & 11.08 & 0.89 & 0.01 \\ 21 & 10.41 & 0.89 & 0.01 \\ 23 & 9.78 & 0.89 & 0.01 \\ 25 & 9.19 & 0.89 & 0.01 \\ 27 & 8.64 & 0.89 & 0.01 \\ 29 & 8.12 & 0.89 & 0.01 \\ 31 & 7.63 & 0.89 & 0.01 \\ 33 & 7.17 & 0.89 & 0.01 \\ 35 & 6.73 & 0.89 & 0.01 \\ 37 & 6.33 & 0.89 & 0.01 \\ 39 & 5.95 & 0.89 & 0.01 \\ 41 & 5.59 & 0.89 & 0.01 \\ 43 & 5.25 & 0.89 & 0.01 \\ 45 & 4.93 & 0.89 & 0.01 \\ 47 & 4.64 & 0.89 & 0.01\end{array}$


Example 1: SIT.PPP File Used in Simulation

\begin{tabular}{|c|c|}
\hline $10 \mathrm{~Pb} 21026.22 \mathrm{yr} \quad \mathrm{dpm} / \mathrm{g}$ & $<=\operatorname{LINE} 1$ \\
\hline 0 on nOSPLINE 5 & $<=$ LINE 2 \\
\hline $\begin{array}{llllll}0 & \text { no } 24 & 0 & 47.0 & 1995\end{array}$ & $\Leftrightarrow=$ LINE 3 \\
\hline $\begin{array}{lllll}\text { V } & 20.0 & 15.0 & 25.0 & .5\end{array}$ & $\Longleftarrow$ LINE 4 \\
\hline $\begin{array}{lllll}\mathrm{V} & 1.0 & .5 & 1.5 & .25\end{array}$ & $<=\operatorname{LINE} 5$ \\
\hline $\begin{array}{lllll}F & 0.0 & -0.9 & 0.90 & 0.10\end{array}$ & $\Leftrightarrow \operatorname{LINE} 6$ \\
\hline $500.0 \mathrm{nP} n \mathrm{P} \mathrm{nP} \mathrm{nP} \mathrm{nP}$ & $\Longleftrightarrow \operatorname{LINE} 7$ \\
\hline $\begin{array}{llll}3 & 0.0 & 0.0 & 1\end{array}$ TIMEFILE.DAT & $<$ LINE 8 \\
\hline no 16.0 no 32.0 & $<=\operatorname{LINE} 9$ \\
\hline 0 & $\Longleftrightarrow$ LINE 10 \\
\hline
\end{tabular}

Example 1: Output File AEX1.OUT

DATA TITLE $=$ Example one.

PROCESSED ON 4/24/1995 AT 15:30.

THE DATA FILE NAME AND LOCATION: C:IPBMODELSLLEADIEXI.DAT

$10 \mathrm{pb} 21026.22 \mathrm{yr} \mathrm{dpm} / \mathrm{g}$

$<$ LINE 1

0 on NOSPLINE 5

$<=$ LINE 2

0 no 24047.01995

$<==$ LINE 3

$\begin{array}{lllll}\mathrm{V} & 20.0 & 15.0 & 25.0 & .5\end{array}$

$<==$ LINE 4

$\begin{array}{lllll}\mathrm{V} & 1.0 & .5 & 1.5 & .25\end{array}$

—LINE 5

$\begin{array}{llllll}F & 0.0 & -0.9 & 0.90 & 0.10\end{array}$

$<==$ LINE 6

$500.0 \mathrm{nP} n \mathrm{P} \mathrm{nP} \mathrm{nP} \mathrm{nP}$

$<=$ LINE 7

$\begin{array}{lllll}3 & 0.0 & 0.0 & 1 & \text { TIMEFILE.DAT }\end{array}$

$<=$ LINE 8

no 16.0 no 32.0

$<=$ LINE 9

PARAMETER FILE INPUT:

MTOM SET TO 0.

MAXIMUM CHI SQUARE VALUE IS 500.000 .

THERE ARE 24 DATA POINTS IN THIS CORE.

THIS CORE WAS PROCESSED FROM THE SURFACE. 
CONTOURING FILE (IS_R_CHI.DAT) IS NOT COMPLETE.

NUMBER OF ITERATIONS FOR ADJUSTING COEF IS 10.

DECAY COEFFICIENT FOR THE ISOTOPE PB210 IS: $3.113869 \mathrm{E}-02$ /yr.

ACTIVITY IS IN UNITS OF: dpm/g.

THE YEAR THE CORE WAS TAKEN: 1995.

NO DATA SPLINING.

THIS IS A LINEAR SEARCH TASK WITH THE FOLLOWING PARAMETERS:

$\begin{array}{ccccc}\text { V } & 20.0000 & 15.0000 & 25.0000 & 0.5000 \\ \text { V } & 1.0000 & 0.5000 & 1.5000 & 0.2500 \\ \text { F } & 0.0000 & -0.9000 & 0.9000 & 0.1000\end{array}$

THERE ARE NO KNOWN TIME TO DEPTH OR VARIANCE VALUES INDICATED.

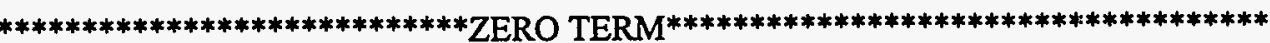

STEP 1

SURFACE $=15.0000 \mathrm{MSR}=6.8620$.

STEP 2

SURFACE $=15.5000$ MSR $=5.5496$.

/I

STEP 10

SURFACE $=19.5000$ MSR $=0.0683$.

STEP 11

SURFACE $=20.0000$ MSR $=0.0000$.

STEP 12

SURFACE $=20.5000$ MSR $=0.0668$.

/I 
STEP 20

SURFACE $=24.5000 \mathrm{MSR}=5.4000$.

STEP 21

SURFACE $=25.0000$ MSR $=6.6596$.

THE PARAMETER(S) ADJUSTED: SURFACE RATE

THE BEST PARAMETERS ARE :

CHI-SQUARED $=\quad 0.0000$ WHICH WAS OBTAINED AT 11TH ITERATION

$\operatorname{PBMAX}=20.0000$

SLOPE $=-0.0311$

WEIGHT $=0.0000$

DEPTH AGE TIME RATE SRCS FLUX DATA MODEL

$\begin{array}{lllllllll}0.00 & 1995 & 0.00 & 0.0000 & 1.00 & 0.00 & 20.000 & 20.000 \\ 1.00 & 1994 & 1.00 & 1.0013 & 1.00 & 17.82 & 19.390 & 19.388 \\ 3.00 & 1992 & 3.00 & 1.0013 & 1.00 & 17.82 & 18.220 & 18.218 \\ 5.00 & 1990 & 4.99 & 1.0013 & 1.00 & 17.82 & 17.120 & 17.120 \\ 7.00 & 1988 & 6.99 & 1.0013 & 1.00 & 17.82 & 16.090 & 16.087 \\ 9.00 & 1986 & 8.99 & 1.0013 & 1.00 & 17.82 & 15.120 & 15.117 \\ 11.00 & 1984 & 10.99 & 1.0013 & 1.00 & 17.82 & 14.210 & 14.206 \\ 13.00 & 1982 & 12.98 & 1.0013 & 1.00 & 17.82 & 13.350 & 13.349 \\ 15.00 & 1980 & 14.98 & 1.0013 & 1.00 & 17.82 & 12.540 & 12.544 \\ 17.00 & 1978 & 16.98 & 1.0013 & 1.00 & 17.82 & 11.790 & 11.787 \\ 19.00 & 1976 & 18.98 & 1.0013 & 1.00 & 17.82 & 11.080 & 11.077 \\ 21.00 & 1974 & 20.97 & 1.0013 & 1.00 & 17.82 & 10.410 & 10.409 \\ 23.00 & 1972 & 22.97 & 1.0013 & 1.00 & 17.82 & 9.780 & 9.781 \\ 25.00 & 1970 & 24.97 & 1.0013 & 1.00 & 17.82 & 9.190 & 9.191 \\ 27.00 & 1968 & 26.97 & 1.0013 & 1.00 & 17.82 & 8.640 & 8.637 \\ 29.00 & 1966 & 28.96 & 1.0013 & 1.00 & 17.82 & 8.120 & 8.116 \\ 31.00 & 1964 & 30.96 & 1.0013 & 1.00 & 17.82 & 7.630 & 7.627\end{array}$




$\begin{array}{llllllll}33.00 & 1962 & 32.96 & 1.0013 & 1.00 & 17.82 & 7.170 & 7.167 \\ 35.00 & 1960 & 34.96 & 1.0013 & 1.00 & 17.82 & 6.730 & 6.734 \\ 37.00 & 1958 & 36.95 & 1.0013 & 1.00 & 17.82 & 6.330 & 6.328 \\ 39.00 & 1956 & 38.95 & 1.0013 & 1.00 & 17.82 & 5.950 & 5.947 \\ 41.00 & 1954 & 40.95 & 1.0013 & 1.00 & 17.82 & 5.590 & 5.588 \\ 43.00 & 1952 & 42.95 & 1.0013 & 1.00 & 17.82 & 5.250 & 5.251 \\ 45.00 & 1950 & 44.94 & 1.0013 & 1.00 & 17.82 & 4.930 & 4.934 \\ 47.00 & 1948 & 46.94 & 1.0013 & 1.00 & 17.82 & 4.640 & 4.637\end{array}$


Input and Output Listings for Example 2: Variable Sediment Accumulation Rate/Variable Isotopic Flux Example Simulation

Example 2: Data File EX2.DAT

Example Two

Depth Pb210 DBD Error

$\begin{array}{llll}0.73 & 1.58 & 0.544 & 0.38\end{array}$

$\begin{array}{llll}2.2 & 2.15 & 0.55 & 0.61\end{array}$

$\begin{array}{llll}3.4 & 1.65 & 0.524 & 0.49\end{array}$

$\begin{array}{llll}4.9 & 1.76 & 0.532 & 0.58\end{array}$

$\begin{array}{llll}6.2 & 1.89 & 0.511 & 0.43\end{array}$

$\begin{array}{llll}7.6 & 2.07 & 0.494 & 0.41\end{array}$

$\begin{array}{llll}8.9 & 1.75 & 0.489 & 0.56\end{array}$

$\begin{array}{llll}10.4 & 3.52 & 0.567 & 0.87\end{array}$

$\begin{array}{llll}11.9 & 3.08 & 0.565 & 0.87\end{array}$

$\begin{array}{llll}13.3 & 2.09 & 0.542 & 2.08\end{array}$

$\begin{array}{llll}14.9 & 2.97 & 0.561 & 0.76\end{array}$

$\begin{array}{llll}16.3 & 1.71 & 0.524 & 0.6\end{array}$

$\begin{array}{llll}17.6 & 1.73 & 0.515 & 0.52\end{array}$

$\begin{array}{lllll}19.0 & 1.8, & 0.499 & 0.63\end{array}$

$\begin{array}{llll}20.2 & 0.66 & 0.465 & 0.52\end{array}$

$\begin{array}{llll}21.5 & 0.93 & 0.462 & 0.51\end{array}$

$\begin{array}{llll}22.6 & 0.22 & 0.426 & 0.33\end{array}$

$\begin{array}{llll}23.6 & 1.01 & 0.373 & 0.57\end{array}$

$\begin{array}{llll}24.8 & 0.5 & 0.455 & 0.44\end{array}$

Example 2: SIT.PPP File Used in Simulation
$10 \mathrm{pb} 21026.22 \mathrm{yr} \mathrm{dpm} / \mathrm{g}$
$<=$ LINE 1
4 on nOSPLINE 5
$<=$ LINE 2
2 no 19024.81993
$<=$ LINE 3
$\begin{array}{lllll}\mathrm{V} & 2.0 & 1.5 & 2.5 & 0.1\end{array}$
$<==$ LINE 4
$\begin{array}{lllll}\mathrm{V} & 0.5 & 0.3 & 0.7 & .05\end{array}$
$\Longleftarrow$ LINE 5 


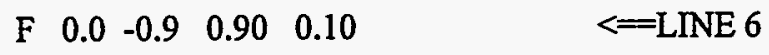

$$
\begin{aligned}
& 0.50 \text { P P P P P } \quad \Longleftrightarrow \text { LINE } 7
\end{aligned}
$$

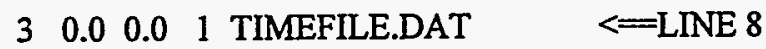

$$
\begin{aligned}
& \text { no } 16.0 \text { yes } 71.0 \quad \Longleftarrow \text { LINE } 9 \\
& 1 \quad<=\text { LINE } 10 \\
& 11.930 .02 .0 \quad \Leftrightarrow \text { LINE } 11
\end{aligned}
$$

Example 2: Output File AEX2.OUT

DATA TITLE = Example two.

\begin{tabular}{|c|c|}
\hline $10 \mathrm{pb} 21026.22 \mathrm{yr} \mathrm{dpm} / \mathrm{g}$ & $<=$ LINE 1 \\
\hline 4 on noSPLINE 5 & $\Leftrightarrow=$ LINE 2 \\
\hline 2 no 19024.81993 & $\Leftrightarrow$ LINE 3 \\
\hline $\begin{array}{lllll}\text { V } & 2.0 & 1.5 & 2.5 & .1\end{array}$ & $<=$ LINE 4 \\
\hline $\begin{array}{lllll}\text { V } & 0.5 & .3 & 0.7 & .05\end{array}$ & $\Longleftrightarrow$ LINE 5 \\
\hline $\begin{array}{lllll}F & 0.0 & -0.9 & 0.90 & 0.10\end{array}$ & $\Longleftrightarrow$ LINE 6 \\
\hline 0.50 P P P P P & $<=\operatorname{LINE} 7$ \\
\hline $\begin{array}{lllll}3 & 0.0 & 0.0 & 1\end{array}$ TIMEFILE.DAT & $<=$ LINE 8 \\
\hline no 16.0 yes 71.0 & $\Longleftrightarrow \operatorname{LINE} 9$ \\
\hline
\end{tabular}

PROCESSED ON 4/24/1995 AT 16:14.

THE DATA FILE NAME AND LOCATION: C:PBMMODELSLLEADIEX2.DAT

PARAMETER FILE INPUT:

MTOM SET TO 4.

MAXIMUM CHI SQUARE VALUE IS 0.500 .

THERE ARE 19 DATA POINTS IN THIS CORE.

THIS CORE WAS PROCESSED FROM THE SURFACE.

CONTOURING FILE (IS_R_CHI.DAT) IS NOT COMPLETE.

NUMBER OF ITERATIONS FOR ADJUSTING COEF IS 10.

DECAY COEFFICIENT FOR THE ISOTOPE PB210 IS: $3.113869 \mathrm{E}-02 . / \mathrm{yr}$

ACTIVITY IS IN UNITS OF : dpm/g

THE YEAR THE CORE WAS TAKEN: 1993.

NO DATA SPLINING. 
THIS IS A LINEAR SEARCH TASK WITH THE FOLLOWING PARAMETERS:
V $\quad 2.0000 \quad 1.5000 \quad 2.5000 \quad 0.1000$
$\begin{array}{lllll}V & 5.0000 & 0.3000 & 0.7000 & 0.0500\end{array}$
$\begin{array}{lllll}\text { F } & 0.0000 & -0.9000 & 0.9000 & 0.1000\end{array}$

THESE ARE THE KNOWN TIME TO DEPTH VALUES WITH A VARIANCE(S).

$11.90 \mathrm{~cm} 30.00$ years $\sigma^{2}=2.000$

\section{LINEAR SEARCH TOMOGRAPHY OUTPUT}

I J PARAMETERS M.S.R -
$\begin{array}{llll}26 & 1.6000 & 0.4500 & 0.4483\end{array}$
$A(n)=-1.66446 \quad 0.67986$
$\mathrm{B}(\mathrm{n})=0.72158 \quad 2.14273$
RELATIVE CHI $=1.000000^{\circ}$
/I
$\begin{array}{llll}71 & 2.1000 & 0.7000 & 0.3026\end{array}$
$A(n)=0.92932 \quad 0.86683$
$B(n)=-0.18119 \quad 4.65701$
RELATIVE $\mathrm{CHI}=1.055037$
$\begin{array}{llll}72 & 2.1000 & 0.6500 & 0.1613\end{array}$
$\mathrm{A}(\mathrm{n})=1.14577 \quad 1.03605$
$B(n)=-0.09755 \quad 4.18788$
RELATIVE CHI $=0.218596$

$\begin{array}{llll}73 & 2.1000 & 0.6000 & 0.1614 \\ A(n)= & 1.12724 & 0.98064 \\ B(n)= & 0.05288 & 4.17472 \\ \text { RELATIVE CHI }= & 1.760392\end{array}$


$\begin{array}{llll}74 & 2.1000 & 0.5500 & 0.2817\end{array}$

$A(n)=1.10533 \quad 0.91516$

$\mathrm{B}(\mathrm{n})=0.23065 \quad 4.15916$

RELATIVE $\mathrm{CHI}=0.371897$

$\begin{array}{llll}81 & 2.2000 & 0.7000 & 0.4383\end{array}$

$A(n)=1.39208 \quad 0.87691$

$\mathrm{B}(\mathrm{n})=-0.18384 \quad 5.07988$

RELATIVE CHI $=1.437696$

$\begin{array}{llll}82 & 2.2000 & 0.6500 & 0.4689\end{array}$

$A(n)=1.379110 .83891$

$B(n)=-0.08070 \quad 5.04452$

RELATIVE CHI $=0.980847$

THE BEST FIT IS GIVEN BY:

$\mathrm{A}(\mathrm{n}) \quad \mathrm{B}(\mathrm{n})$

$1.14577-0.09755$

$1.03605 \quad 4.18788$

THE CHI-SQUARED FOR DATA TO MODEL IS 0.1613.

The Parameters adjusted: SURFACE and RATE.

I J PARAMETERS CHI RELATIVE CHI

$\begin{array}{llllll}72 & 2.1000 & 0.6500 & 0.1613 & 0.110439\end{array}$

DEPTH AGE TIME RATE SRCS FLUX DATA MODEL

$\begin{array}{llllllll}0.00 & 1993 & 0.00 & 0.0000 & 1.00 & 0.00 & 2.100 & 2.100\end{array}$

$\begin{array}{llllllll}0.73 & 1989 & 3.18 & 0.2297 & 1.01 & 0.27 & 1.580 & 1.924\end{array}$

$\begin{array}{llllllll}2.20 & 1983 & 9.41 & 0.2360 & 1.10 & 0.30 & 2.150 & 1.731\end{array}$

$\begin{array}{llllllll}3.40 & 1978 & 14.14 & 0.2536 & 1.26 & 0.35 & 1.650 & 1.701\end{array}$

$\begin{array}{lllllllll}4.90 & 1973 & 19.36 & 0.2872 & 1.56 & 0.50 & 1.760 & 1.794\end{array}$

$\begin{array}{llllllll}6.20 & 1969 & 23.12 & 0.3463 & 1.93 & 0.72 & 1.890 & 1.973\end{array}$ 


$\begin{array}{cccccccc}7.60 & 1966 & 26.27 & 0.4437 & 2.42 & 1.11 & 2.070 & 2.245 \\ 8.90 & 1964 & 28.38 & 0.6176 & 2.92 & 1.85 & 1.750 & 2.530 \\ 10.40 & 1963 & 29.91 & 0.9790 & 3.41 & 3.97 & 3.520 & 2.820 \\ 11.90 & 1962 & 30.67 & 1.9809 & 3.66 & 8.61 & 3.080 & 2.961 \\ 13.30 & 1962 & 30.90 & 5.9508 & 3.60 & 24.39 & 2.090 & 2.889 \\ 14.90 & 1962 & 30.92 & 89.334 & 3.20 & 336.7 & 2.970 & 2.566 \\ 16.30 & 1962 & 30.97 & 28.872 & 2.68 & 85.29 & 1.710 & 2.149 \\ 17.60 & 1961 & 31.21 & 5.3027 & 2.19 & 12.55 & 1.730 & 1.739 \\ 19.00 & 1961 & 31.81 & 2.3260 & 1.72 & 4.20 & 1.800 & 1.345 \\ 20.20 & 1960 & 32.66 & 1.4259 & 1.41 & 1.97 & 0.660 & 1.074 \\ 21.50 & 1959 & 33.90 & 1.0429 & 1.17 & 1.19 & 0.930 & 0.858 \\ 22.60 & 1957 & 35.19 & 0.8542 & 1.04 & 0.80 & 0.220 & 0.731 \\ 23.60 & 1956 & 36.50 & 0.7658 & 0.97 & 0.58 & 1.010 & 0.653 \\ 24.80 & 1954 & 38.15 & 0.7238 & 0.94 & 0.65 & 0.500 & 0.602\end{array}$

Probability Density File Information From Example 2

\section{TIME.PRO}

Number of Time Values: 17

\begin{tabular}{|c|c|c|c|c|c|c|c|c|c|c|}
\hline DEPTH & MN & $\operatorname{MAX}$ & P_68 & P_90 & $P_{-} 10$ & (P90-P, 68) & $\left(P_{-} 68-P_{-} 10\right)$ & VoL. & RISK & RELATTVE RISK \\
\hline 0.000 & 0.00 & 0.000 & 0.000 & 0.000 & 0.000 & 0.000 & 0.000 & 0.000 & 0.000 & 0.000 \\
\hline 0.730 & 1.603 & 3.202 & 2.683 & 2.865 & 1.436 & 0.182 & 1.246 & 0.533 & 0.808 & 0.202 \\
\hline 2.200 & 4.708 & 9.488 & 7.955 & 8.487 & 4.322 & 0.531 & 3.633 & 0.523 & 2.436 & 0.610 \\
\hline 3.400 & 7.127 & 14.28 & 12.026 & 12.805 & 6.701 & 0.779 & 5.325 & 0.508 & 3.798 & 0.951 \\
\hline 4.900 & 10.453 & 19.61 & 16.679 & 17.704 & 9.665 & 1.026 & 7.014 & 0.482 & 5.546 & 1.389 \\
\hline 6.200 & 13.565 & 23.494 & 20.248 & 21.412 & 12.288 & 1.164 & 7.960 & 0.451 & 7.202 & 1.804 \\
\hline 7.600 & 17.147 & 26.825 & 23.548 & 24.750 & 15.334 & 1.201 & 8.214 & 0.400 & 9.441 & 2.364 \\
\hline 8.900 & 20.622 & 29.127 & 26.133 & 27.245 & 18.526 & 1.112 & 7.607 & 0.334 & 12.555 & 3.144 \\
\hline 10.400 & 24.438 & 30.921 & 28.550 & 29.404 & 22.710 & 0.854 & 5.840 & 0.234 & 19.518 & 4.888 \\
\hline 11.900 & 28.118 & 31.966 & 30.946 & 31.548 & 26.831 & 0.602 & 4.115 & 0.152 & 32.542 & 8.150 \\
\hline 13.300 & 30.842 & 35.665 & 33.700 & 34.316 & 29.488 & 0.616 & 4.213 & 0.143 & 37.701 & 9.442 \\
\hline 14.900 & 30.919 & 39.842 & 37.319 & 38.162 & 31.555 & 0.843 & 5.764 & 0.177 & 33.787 & 8.462 \\
\hline 16.300 & 30.967 & 43.347 & 40.750 & 41.893 & 32.934 & 1.143 & 7.816 & 0.220 & 29.709 & 7.440 \\
\hline 17.600 & 31.212 & 46.736 & 44.054 & 45.475 & 34.333 & 1.421 & 9.721 & 0.253 & 27.919 & 6.992 \\
\hline 19.000 & 31.814 & 50.547 & 47.755 & 49.461 & 36.083 & .1 .707 & 11.672 & 0.280 & 27.323 & 6.843 \\
\hline
\end{tabular}




$\begin{array}{lllllllllll}20.200 & 32.656 & 53.920 & 51.030 & 52.961 & 37.827 & 1.931 & 13.203 & 0.297 & 27.581 & 6.907 \\ 21.500 & 33.902 & 57.705 & 54.677 & 56.826 & 39.982 & 2.149 & 14.695 & 0.308 & 28.449 & 7.125 \\ 22.600 & 35.190 & 61.039 & 57.802 & 60.106 & 42.045 & 2.304 & 15.757 & 0.312 & 29.652 & 7.426 \\ 23.600 & 36.496 & 64.081 & 60.676 & 63.114 & 44.010 & 2.437 & 16.667 & 0.315 & 30.891 & 7.736 \\ 24.800 & 38.154 & 67.736 & 64.152 & 66.746 & 46.409 & 2.594 & 17.742 & 0.317 & 32.437 & 8.124\end{array}$

\section{RATE.PRO}

Number of Time Values: 17

\begin{tabular}{|c|c|c|c|c|c|c|c|c|c|c|}
\hline DEPTH & $\operatorname{MIN}$ & $\max$ & P_68 & P_90 & P_10 & (P90-P_68) & (P_68-P_10) & voL. & RISK & RELATIVE RISK \\
\hline 0.000 & 0.000 & 0.000 & 0.000 & 0.000 & 0.000 & 0.000 & 0.000 & 0.000 & 0.000 & 0.000 \\
\hline 0.730 & 0.228 & 0.455 & 0.400 & 0.424 & 0.231 & 0.025 & 0.168 & 0.483 & 0.053 & 0.520 \\
\hline 2.200 & 0.234 & 0.473 & 0.405 & 0.430 & 0.237 & 0.025 & 0.169 & 0.477 & 0.054 & 0.533 \\
\hline 3.400 & 0.250 & 0.496 & 0.412 & 0.437 & 0.248 & 0.024 & 0.165 & 0.458 & 0.058 & 0.566 \\
\hline 4.900 & 0.281 & 0.451 & 0.414 & 0.433 & 0.280 & 0.020 & 0.134 & 0.371 & 0.071 & 0.701 \\
\hline 6.200 & 0.335 & 0.492 & 0.429 & 0.446 & 0.312 & 0.017 & 0.117 & 0.313 & 0.088 & 0.860 \\
\hline 7.600 & 0.366 & 0.548 & 0.456 & 0.474 & 0.338 & 0.017 & 0.118 & 0.297 & 0.098 & 0.964 \\
\hline 8.900 & 0.362 & 0.618 & 0.515 & 0.541 & 0.338 & 0.026 & 0.177 & 0.393 & 0.084 & 0.823 \\
\hline 10.400 & 0.361 & 0.979 & 0.710 & 0.777 & 0.250 & 0.067 & 0.459 & 0.742 & 0.061 & 0.601 \\
\hline 11.900 & 0.364 & 1.981 & 1.267 & 1.462 & -0.068 & 0.195 & 1.334 & 1.207 & 0.067 & 0.659 \\
\hline 13.300 & 0.370 & 5.951 & 3.997 & 4.677 & -0.652 & 0.680 & 4.649 & 1.333 & 0.192 & 1.883 \\
\hline 14.900 & 0.383 & 89.335 & 78.089 & 84.898 & 31.52 & 6.809 & 46.566 & 0.684 & 7.322 & 71.778 \\
\hline 16.300 & 0.370 & 28.873 & 23.217 & 25.975 & 4.351 & 2.759 & 18.865 & 0.931 & 1.598 & 15.661 \\
\hline 17.600 & 0.356 & 5.303 & 3.647 & 4.288 & -0.732 & 0.640 & 4.379 & 1.376 & 0.170 & 1.665 \\
\hline 19.000 & 0.343 & 2.326 & 1.569 & 1.857 & -0.400 & 0.288 & 1.969 & 1.438 & 0.070 & 0.686 \\
\hline 20.200 & 0.337 & 1.426 & 0.978 & 1.142 & -0.141 & 0.164 & 1.119 & 1.311 & 0.048 & 0.469 \\
\hline 21.500 & 0.328 & 1.043 & 0.735 & 0.842 & 0.009 & 0.106 & 0.727 & 1.133 & 0.042 & 0.408 \\
\hline 22.600 & 0.310 & 0.854 & 0.618 & 0.694 & 0.094 & 0.077 & 0.524 & 0.972 & 0.041 & 0.399 \\
\hline 23.600 & 0.299 & 0.766 & 0.563 & 0.626 & 0.136 & 0.062 & 0.427 & 0.870 & 0.042 & 0.407 \\
\hline 24.800 & 0.293 & 0.724 & 0.538 & 0.594 & 0.157 & 0.056 & 0.382 & 0.813 & 0.042 & 0.416 \\
\hline
\end{tabular}




\section{SOURCE.PRO}

Number of Time Values: 17

\begin{tabular}{|c|c|c|c|c|c|c|c|c|c|c|}
\hline DEPTH & $\mathbf{M} \mathbb{N}$ & $\max$ & P_68 & $P_{-} 90$ & $P_{-} 10$ & (P_90-P_68) & (P_68-P_10) & VOL & RISK & RELATIVE RISK \\
\hline 0.00 & 0.00 & 0.00 & 0.00 & 0.00 & 0.00 & 0.00 & 0.00 & 0.00 & 0.00 & 0.00 \\
\hline 0.73 & 1.01 & 1.01 & 1.01 & 1.01 & 1.01 & 0.00 & 0.00 & 0.01 & 22.96 & 58.91 \\
\hline 2.20 & 1.07 & 1.13 & 1.11 & 1.12 & 1.07 & 0.01 & 0.04 & 0.04 & 2.90 & 7.44 \\
\hline 3.40 & 1.16 & 1.31 & 1.27 & 1.28 & 1.17 & 0.02 & 0.10 & 0.09 & 1.49 & 3.82 \\
\hline 4.90 & 1.35 & 1.69 & 1.59 & 1.63 & 1.35 & 0.04 & 0.24 & 0.17 & 1.02 & 2.61 \\
\hline 6.20 & 1.56 & 2.17 & 1.99 & 2.06 & 1.58 & 0.06 & 0.42 & 0.24 & 0.92 & 2.35 \\
\hline 7.60 & 1.83 & 2.85 & 2.55 & 2.65 & 1.88 & 0.10 & 0.67 & 0.30 & 0.93 & 2.38 \\
\hline 8.90 & 2.10 & 3.55 & 3.12 & 3.26 & 2.19 & 0.14 & 0.94 & 0.34 & 1.00 & 2.57 \\
\hline 10.40 & 2.38 & 4.27 & 3.73 & 3.91 & 2.53 & 0.18 & 1.20 & 0.37 & 1.12 & 2.86 \\
\hline 11.90 & 2.56 & 4.67 & 4.11 & 4.30 & 2.78 & 0.19 & 1.33 & 0.37 & 1.22 & 3.14 \\
\hline 13.30 & 2.61 & 4.62 & 4.15 & 4.34 & 2.83 & 0.19 & 1.32 & 0.37 & 1.25 & 3.21 \\
\hline 14.90 & 2.51 & 4.76 & 3.88 & 4.07 & 2.56 & 0.19 & 1.31 & 0.39 & 1.10 & 2.83 \\
\hline 16.30 & 2.32 & 4.62 & 3.51 & 3.73 & 2.03 & 0.22 & 1.48 & 0.49 & 0.80 & 2.05 \\
\hline 17.60 & 2.09 & 4.34 & 3.16 & 3.42 & 1.40 & 0.26 & 1.76 & 0.64 & 0.55 & 1.40 \\
\hline 19.00 & 1.73 & 3.96 & 2.80 & 3.08 & 0.86 & 0.28 & 1.94 & 0.79 & 0.39 & 1.00 \\
\hline 20.20 & 1.41 & 3.63 & 2.49 & 2.76 & 0.65 & 0.27 & 1.84 & 0.85 & 0.33 & 0.83 \\
\hline 21.50 & 1.17 & 3.34 & 2.24 & 2.49 & 0.52 & 0.25 & 1.72 & 0.88 & 0.28 & 0.72 \\
\hline 22.60 & 1.04 & 3.15 & 2.09 & 2.33 & 0.45 & 0.24 & 1.64 & 0.90 & 0.26 & 0.66 \\
\hline 23.60 & 0.97 & 3.05 & 2.00 & 2.24 & 0.41 & 0.23 & 1.60 & 0.91 & 0.24 & 0.62 \\
\hline 24.80 & 0.94 & 3.00 & 1.97 & 2.20 & 0.39 & 0.23 & 1.58 & 0.92 & 0.24 & 0.61 \\
\hline
\end{tabular}

\section{FLUX.PRO}

Number of Time Values: 17

\begin{tabular}{|c|c|c|c|c|c|c|c|c|c|c|}
\hline DEPTH & MIN & $\operatorname{MAX}$ & P_68 & $P_{-} 90$ & $P_{-} 10$ & (P_90-P_68) & (P_68-P_10) & voL. & RISK & RELATIVE RUSK \\
\hline 0.00 & 0.00 & 0.00 & 0.00 & 0.00 & 0.00 & 0.00 & 0.00 & 0.00 & 0.00 & 0.00 \\
\hline 0.73 & 0.26 & 0.45 & 0.40 & 0.42 & 0.27 & 0.02 & 0.13 & 0.36 & 0.08 & 0.19 \\
\hline 2.20 & 0.30 & 0.51 & 0.45 & 0.47 & 0.31 & 0.02 & 0.14 & 0.35 & 0.09 & 0.22 \\
\hline 3.40 & 0.35 & 0.57 & 0.49 & 0.51 & 0.35 & 0.02 & 0.14 & 0.33 & 0.11 & 0.26 \\
\hline 4.90 & 0.48 & 0.69 & 0.63 & 0.66 & 0.46 & 0.03 & 0.17 & 0.31 & 0.15 & 0.36 \\
\hline 6.20 & 0.53 & 0.92 & 0.81 & 0.85 & 0.57 & 0.04 & 0.25 & 0.35 & 0.17 & 0.41 \\
\hline 7.60 & 0.60 & 1.34 & 1.13 & 1.20 & 0.67 & 0.07 & 0.46 & 0.46 & 0.18 & 0.43 \\
\hline 8.90 & 0.69 & 1.85 & 1.60 & 1.72 & 0.79 & 0.12 & 0.81 & 0.58 & 0.20 & 0.48 \\
\hline
\end{tabular}




$\begin{array}{lllllllllll}10.40 & 0.94 & 3.97 & 3.05 & 3.35 & 1.05 & 0.29 & 2.00 & 0.75 & 0.30 & 0.71 \\ 11.90 & 1.03 & 8.61 & 5.43 & 6.12 & 0.67 & 0.70 & 4.76 & 1.01 & 0.39 & 0.94 \\ 13.30 & 1.03 & 24.39 & 15.98 & 18.36 & -0.25 & 2.37 & 16.23 & 1.16 & 1.00 & 2.40 \\ 14.90 & 1.06 & 336.75 & 294.01 & 318.69 & 125.19 & 24.69 & 168.82 & 0.66 & 32.49 & 78.12 \\ 16.30 & 0.91 & 85.29 & 67.88 & 75.74 & 14.14 & 7.86 & 53.74 & 0.91 & 5.44 & 13.08 \\ 17.60 & 0.79 & 12.56 & 8.46 & 9.88 & -1.22 & 1.42 & 9.69 & 1.31 & 0.47 & 1.13 \\ 19.00 & 0.65 & 4.20 & 2.81 & 3.27 & -0.33 & 0.46 & 3.14 & 1.28 & 0.16 & 0.38 \\ 20.20 & 0.52 & 1.97 & 1.38 & 1.56 & 0.12 & 0.19 & 1.26 & 1.05 & 0.10 & 0.23 \\ 21.50 & 0.41 & 1.19 & 0.91 & 1.00 & 0.26 & 0.10 & 0.65 & 0.82 & 0.08 & 0.19 \\ 22.60 & 0.33 & 0.82 & 0.67 & 0.73 & 0.25 & 0.06 & 0.41 & 0.71 & 0.07 & 0.16 \\ 23.60 & 0.26 & 0.69 & 0.52 & 0.57 & 0.21 & 0.05 & 0.31 & 0.68 & 0.06 & 0.14 \\ 24.80 & 0.31 & 0.83 & 0.61 & 0.66 & 0.25 & 0.05 & 0.35 & 0.67 & 0.07 & 0.16\end{array}$




\section{MODEL.PRO}

Number of Time Values: 17

$\begin{array}{lllllllllll}\text { DEPTH } & \text { MIN } & \text { MAX } & \text { P_68 } & \text { P_90 } & \text { P_10 } & \text { (P_90.P68) (P_68-P_10) } & \text { VOL. } & \text { RISK } & \text { RELATIVERISK } \\ 0.000 & 1.600 & 2.200 & 2.070 & 2.129 & 1.666 & 0.059 & 0.404 & 0.224 & 1.085 & 8.418 \\ 0.730 & 1.527 & 2.058 & 1.936 & 1.985 & 1.595 & 0.050 & 0.340 & 0.201 & 1.128 & 8.748 \\ 2.200 & 1.450 & 1.952 & 1.830 & 1.877 & 1.508 & 0.047 & 0.321 & 0.201 & 1.067 & 8.273 \\ 3.400 & 1.445 & 2.011 & 1.871 & 1.926 & 1.494 & 0.055 & 0.377 & 0.231 & 0.952 & 7.382 \\ 4.900 & 1.495 & 2.247 & 2.053 & 2.126 & 1.554 & 0.073 & 0.499 & 0.279 & 0.865 & 6.705 \\ 6.200 & 1.572 & 2.576 & 2.311 & 2.407 & 1.654 & 0.096 & 0.657 & 0.326 & 0.833 & 6.457 \\ 7.600 & 1.672 & 3.026 & 2.659 & 2.786 & 1.788 & 0.127 & 0.871 & 0.375 & 0.832 & 6.449 \\ 8.900 & 1.758 & 3.464 & 2.983 & 3.140 & 1.911 & 0.157 & 1.072 & 0.412 & 0.850 & 6.595 \\ 10.400 & 1.819 & 3.878 & 3.267 & 3.451 & 2.005 & 0.185 & 1.262 & 0.443 & 0.866 & 6.717 \\ 11.900 & 1.803 & 3.861 & 3.289 & 3.474 & 2.022 & 0.185 & 1.266 & 0.441 & 0.875 & 6.785 \\ 13.300 & 1.659 & 3.432 & 3.035 & 3.198 & 1.919 & 0.163 & 1.115 & 0.421 & 0.846 & 6.560 \\ 14.900 & 1.425 & 2.641 & 2.532 & 2.661 & 1.645 & 0.130 & 0.886 & 0.401 & 0.741 & 5.745 \\ 16.300 & 1.192 & 2.178 & 2.047 & 2.156 & 1.308 & 0.108 & 0.740 & 0.414 & 0.580 & 4.501 \\ 17.600 & 0.980 & 1.822 & 1.645 & 1.745 & 0.962 & 0.100 & 0.683 & 0.476 & 0.406 & 3.146 \\ 19.000 & 0.780 & 1.475 & 1.286 & 1.380 & 0.648 & 0.093 & 0.638 & 0.568 & 0.266 & 2.060 \\ 20.200 & 0.627 & 1.220 & 1.035 & 1.116 & 0.481 & 0.081 & 0.554 & 0.614 & 0.198 & 1.536 \\ 21.500 & 0.446 & 0.997 & 0.824 & 0.889 & 0.379 & 0.065 & 0.445 & 0.619 & 0.156 & 1.212 \\ 22.600 & 0.349 & 0.852 & 0.696 & 0.751 & 0.319 & 0.055 & 0.377 & 0.621 & 0.132 & 1.020 \\ 23.600 & 0.292 & 0.750 & 0.612 & 0.661 & 0.280 & 0.049 & 0.333 & 0.623 & 0.115 & 0.896 \\ 24.800 & 0.251 & 0.661 & 0.547 & 0.591 & 0.248 & 0.044 & 0.299 & 0.627 & 0.103 & 0.795\end{array}$




\section{Input and Output Listings for Example 3: Introductory Core Cutting}

\section{Example 3: Data File EX3.DAT}

Example Three

\begin{tabular}{|c|c|c|c|}
\hline Depth(cm) & Data(dpm/g) & \multicolumn{2}{|c|}{$\mathrm{DBD}\left(\mathrm{g} / \mathrm{cm}^{3}\right)$ error( $\left.\mathrm{dpm} / \mathrm{g}\right)$} \\
\hline 0.5 & 2.0 & 0.544 & 0.4 \\
\hline 0.73 & 2.05 & 0.544 & 0.38 \\
\hline 1.4 & 2.1 & 0.544 & 0.45 \\
\hline 1.9 & 2.03 & 0.5 & 0.39 \\
\hline 2.2 & 2.15 & 0.55 & 0.61 \\
\hline 3.0 & 2.0 & 0.524 & 0.49 \\
\hline 5.0 & 2.07 & 0.532 & 0.58 \\
\hline 6.0 & 2.01 & 0.511 & 0.43 \\
\hline 7.5 & 2.07 & 0.494 & 0.41 \\
\hline 9.0 & 1.75 & 0.489 & 0.56 \\
\hline 10.0 & 3.52 & 0.567 & 0.87 \\
\hline 12.0 & 3.08 & 0.565 & 0.87 \\
\hline 13.0 & 2.09 & 0.542 & 2.08 \\
\hline 15.0 & 2.97 & 0.561 & 0.76 \\
\hline 16.0 & 1.71 & 0.524 & 0.6 \\
\hline 17.5 & 1.73 & 0.515 & 0.52 \\
\hline 19.0 & 1.8 & 0.499 & 0.63 \\
\hline 20.0 & 0.66 & 0.465 & 0.52 \\
\hline 21.5 & 0.93 & 0.462 & 0.51 \\
\hline 22.0 & 0.22 & 0.426 & 0.33 \\
\hline 23.0 & 1.01 & 0.373 & 0.57 \\
\hline 24.0 & 0.5 & 0.455 & 0.44 \\
\hline
\end{tabular}

Example 3: SIT.PPP File Used in Simulation
$10 \quad \mathrm{pb} 21026.22 \mathrm{yr} \mathrm{dpm} / \mathrm{g}$
$<$ LINE 1
3 on nOSPLINE 5
«INE 2
2 no 19024.81995
$<=$ LINE 3 
$\begin{array}{lllll}\mathrm{V} & 2.0 & 1.5 & 3.5 & 0.25\end{array}$

$\begin{array}{lllll}\mathrm{V} & 0.2 & 0.1 & 1.0 & 0.1\end{array}$

$\begin{array}{lllll}F & 0.0 & -0.9 & 0.90 & 0.10\end{array}$

$20.0 \mathrm{nP} n \mathrm{P} \mathrm{nP} \mathrm{nP} \mathrm{nP}$

$\begin{array}{llllll}3 & 0.0 & 0.0 & 1 & \text { TIMEFILE.DAT }\end{array}$

no 16.0 no 70.0

1

12.032 .02 .0
$<=$ LINE 4

$<==$ LINE 5

—LINE 6

$<=$ LINE 7

$<=$ LINE 8

$<$ LINE 9

$<=$ LINE 10

$<=$ LINE 11 
Example 3: Output File AEX3.OUT

DATA TITLE $=$ Example Three.

PROCESSED ON 4/26/1995 AT 10:46.

THE DATA FILE NAME AND LOCATION: C:IPBMODELSLLEDIEX3.DAT

$20 \mathrm{pb} 21026.22 \mathrm{yr} \mathrm{dpm} / \mathrm{g}$

$<=$ LINE 1

3 on nOSPLINE 5

$\Longleftrightarrow$ LINE 2

2 yes 2207.51995

$<$ LINE 3

$\begin{array}{llll}\mathrm{V} & 2.0 & 1.5 & 3.5 .25\end{array}$

$\Longleftrightarrow$ LINE 4

$\begin{array}{lllll}\mathrm{V} & 0.2 & .10 & 1.0 & .1\end{array}$

$<$ LINE 5

$\begin{array}{llllllll}F & 0.0 & -0.9 & 0.90 & 0.10\end{array}$

$<=$ LINE 6

$20.0 \mathrm{nP} n \mathrm{P} \mathrm{nP} \mathrm{nP} \mathrm{nP}$

$<$ LINE 7

$\begin{array}{lllll}3 & 0.0 & 0.0 & 1 & \text { TIMEFILE.DAT }\end{array}$

$<=$ LINE 8

no 16.0 no 300.0

$\Leftrightarrow \operatorname{LINE} 10$

\section{PARAMETER FILE INPUT:}

MTOM SET TO 3.

MAXIMUM CHI SQUARE VALUE IS 20.000 .

THERE ARE 22 DATA POINTS IN THIS CORE.

THIS CORE WAS PROCESSED FROM THE SURFACE.

THIS CORE WAS PROCESSED FOR A CONTOUR (ACCEPT ALL ANSWERS).

NUMBER OF ITERATIONS FOR ADJUSTING COEF IS 20.

DECAY COEFFICIENT FOR THE ISOTOPE PB210 IS: 3.113869E-02.

THE YEAR THE CORE WAS TAKEN: 1995.

NO DATA SPLINING.

THIS DATA HAS BEEN BROKEN INTO PARTS WITH 2 TERMS.

THIS IS A LINEAR SEARCH TASK WITH THE FOLLOWING PARAMETERS:
V $\quad 2.0000 \quad 1.5000 \quad 3.5000 \quad 0.2500$
$\begin{array}{lllll}\mathrm{V} & 0.2000 & 0.1000 & 1.0000 & 0.1000\end{array}$
F $\quad 0.0000 \quad-0.9000 \quad 0.9000 \quad 0.1000$ 
THESE ARE THE KNOWN TIME TO DEPTH VALUES WITH A VARIANCE(S).

$12.00 \mathrm{~cm} 32.00$ years $\sigma^{2}=2.000$

THE BEST FIT IS GIVEN BY:

$$
\begin{array}{ll}
A(n) & B(n) \\
-0.62786 & 2.34426 \\
0.80183 & 0.28516
\end{array}
$$

THE CHI-SQUARED FOR DATA TO MODEL IS 0.1507.

The Parameters adjusted: SURFACE and RATE.

SURFACE $=2.2500$ AND RATE $=0.3000$ WITH AN M.S.R. $=0.1507$

\begin{tabular}{lllllll}
\multicolumn{1}{c}{ DEPTH AGE } & \multicolumn{2}{l}{ TIME RATE } & SRCS & DATA & MODEL \\
0.00 & 1995 & 0.00 & 0.0000 & 1.00 & 2.25 & 2.25 \\
0.50 & 1993 & 1.82 & 0.2743 & 1.00 & 2.01 & 2.13 \\
0.73 & 1992 & 2.66 & 0.2760 & 1.01 & 2.05 & 2.09 \\
1.40 & 1990 & 5.04 & 0.2805 & 1.03 & 2.10 & 1.98 \\
1.90 & 1988 & 6.77 & 0.2898 & 1.05 & 2.03 & 1.92 \\
2.20 & 1987 & 7.77 & 0.2986 & 1.07 & 2.15 & 1.90 \\
3.00 & 1985 & 10.32 & 0.3147 & 1.14 & 2.00 & 1.86 \\
5.00 & 1979 & 15.64 & 0.3754 & 1.40 & 2.07 & 1.94 \\
6.00 & 1977 & 17.77 & 0.4708 & 1.59 & 2.01 & 2.06 \\
7.50 & 1974 & 20.52 & 0.5450 & 1.95 & 2.07 & 2.31 \\
9.00 & 1972 & 23.22 & 0.5556 & 2.39 & 1.75 & 2.61 \\
10.00 & 1970 & 25.30 & 0.4815 & 2.71 & 3.52 & 2.78 \\
12.00 & 1964 & 30.88 & 0.3586 & 3.39 & 3.08 & 2.92 \\
13.00 & 1960 & 34.60 & 0.2685 & 3.70 & 2.09 & 2.84 \\
15.00 & 1951 & 44.01 & 0.2125 & 4.20 & 2.97 & 2.40 \\
16.00 & 1945 & 49.52 & 0.1814 & 4.36 & 1.71 & 2.10 \\
17.50 & 1937 & 58.33 & 0.1703 & 4.45 & 1.73 & 1.63
\end{tabular} .

